\title{
SANT JULIÀ DE RAMIS Y PUIG ROM: DOS EJEMPLOS DE YACIMIENTOS CON ARMAMENTO Y EQUIPAMIENTO MILITAR VISIGODO EN EL NORESTE PENINSULAR
}

\author{
POR
}

\author{
GUSTAVO GARCÍA JIMÉNEZ y DAVID VIVÓ I CODINA
}

\section{RESUMEN - ABSTRACT}

Presentamos en este trabajo un conjunto de armas y objetos relacionados con el equipamiento militar de principios del siglo VIII procedente de dos yacimientos de la provincia de Girona: el castellum de Sant Julià de Ramis (en el municipio del mismo nombre), y el castro de Puig Rom (en Roses). El estudio comparado de estos materiales nos ha permitido recomponer una panoplia bastante completa que incluye varios tipos de cuchillos y puñales, manillas de escudo, hachas, puntas de lanza y jabalina, regatones, puntas de flecha, hebillas de cinturón y algunas hebillas y elementos de arnés de caballo.

We present in this work a couple of weapons and objects related to the military equipment of early VIII century from two sites on Girona's province: the castellum of Sant Julià de Ramis (in the municipality of the same name), and the fort of Puig Rom (in Roses). The comparation of these materials has permitted to recompose a quite complete panoply with various types of knives and daggers, shield-handles, axes, spearheads and javelinheads, tips (regatones), arrowheads, belt-buckles and some buckles and horse harness elements.

\section{PALABRAS CLAVE - KEY WORDS}

Armamento visigodo. Sant Julià de Ramis. Puig Rom. Ejércitos germánicos.

Visigothic armament. Sant Julià de Ramis. Puig Rom. Germanic armies.

\section{Procedencia del MATerial}

El material que presentamos a continuación procede de dos yacimientos de la provincia de Girona muy próximos entre sí tanto geográfica como culturalmente (Fig. 1):

El castellum de Sant Julià de Ramis se situa en un punto muy cercano a la ciudad de Girona (dentro del término municipal de St. Julià de Ramis), en lo alto de un cerro en forma de terraza alargada defendida por abruptos desniveles naturales al norte, sur i oeste. Este lugar fue escogido, precisamente por sus posibilidades defensivas, para establecer en él un poblado ibérico (Burch et alii, 2001) que perduraría hasta la fundación de Gerunda. La parte occidental de la terraza fue reocupada en su día por un edificio bajoimperial de carácter militar (castellum) relacionado con el emplazamiento de una torre con control visual sobre la Via Augusta (Burch et alii, 2002: 232). Este edificio se mantuvo en uso, con reformas significativas, hasta el fin del dominio visigodo sobre la zona. 


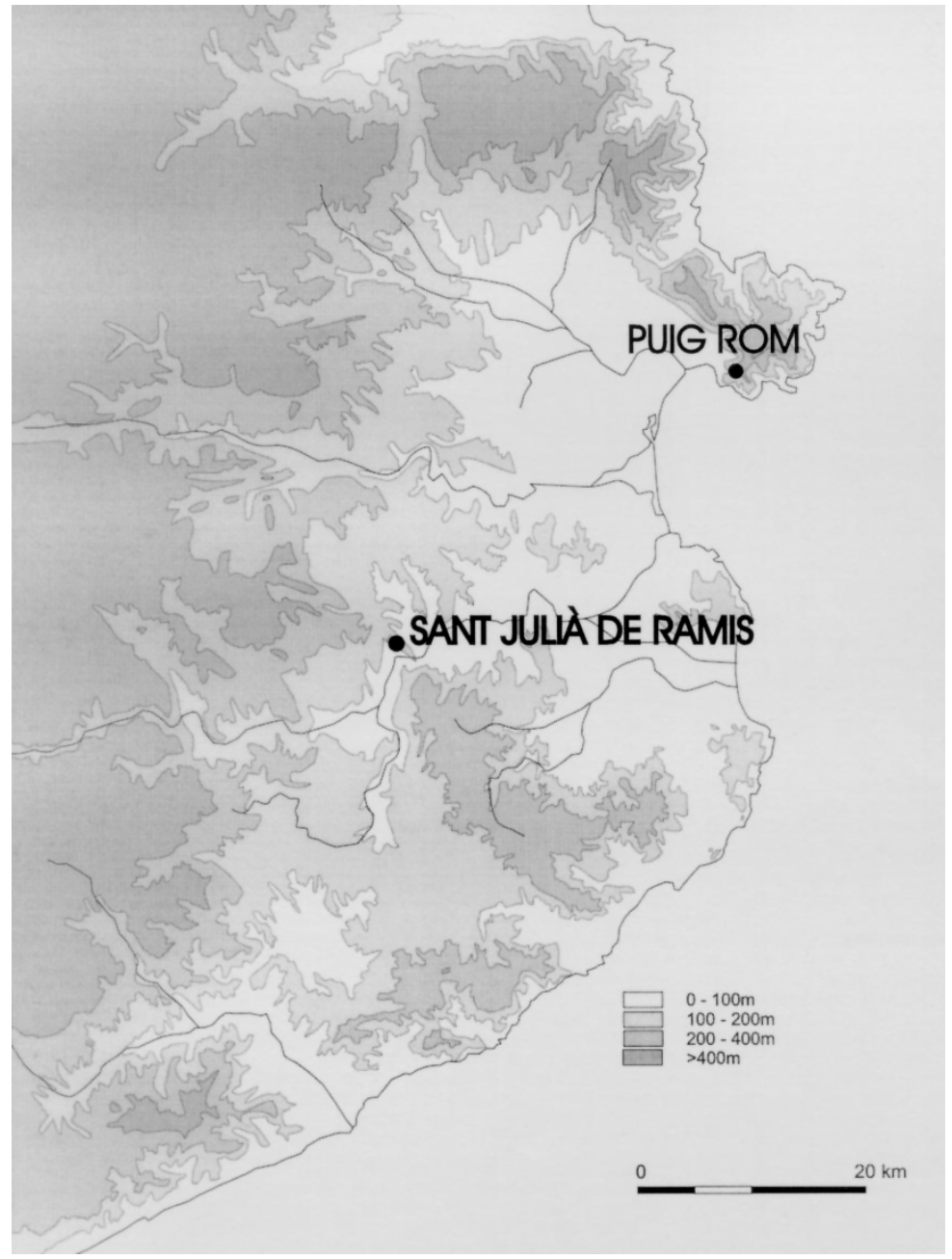

Fig. 1. Mapa de situación.

El castro de Puig Rom (en el municipio de Roses) comparte con el de St. Julià de Ramis su control visual sobre la zona norte, además de su situación en un lugar elevado muy defendible con un único punto accesible, en este caso al sur. El poblado se rodea de un sólido recinto amurallado con tres torres defendiendo su única entrada, localizada en la zona de acceso más vulnerable (Palol, 1952a). La fundación de la plaza hay que relacionarla con la inestabilidad política sufrida a raíz de la revuelta de la Septimania contra el rey Wamba (VV.AA., 1999: 159), mientras que su momento final enlaza con el de Sant Julià de Ramis.

En efecto, ambos yacimientos fueron abandonados muy a principios del siglo VIII coincidiendo muy probablemente con la ocupación musulmana de la zona del noreste peninsular (Palol, 1952a: 181; VV. AA, en prep.), dejando en sus estratos de abandono algunas huellas de la actividad militar que allí se desarrollaba y que nosotros podemos ahora rastrear débilmente.

Todas las armas y elementos de la panoplia procedentes de St. Julià de Ramis provienen de las excavaciones que se han ido realizando desde la Universitat de Girona en el periodo que va del año 1996 al 2001 (VV. AA., en prep.), mientras que los de Puig Rom proceden de los hallazgos realizados por Pere de Palol durante los años 1946 y 1947 (Palol, 1952a), conservados actualmente en su mayoria en los almacenes del MAC-Girona. 


\section{LA PROBLEMATICA DEL ARMAMENTO VISIGODO}

El estudio del armamento visigodo peninsular se encuentra aún en una fase que podríamos denominar como «formativa» en tanto que existen aún hoy día algunos vacíos de registro que habrá que ir completando poco a poco. El tema específico de este tipo de armamento no ha sido fruto de trabajo sistemático desde hace ya algún tiempo, y por entonces se realizó en condiciones no del todo favorables:

Bruhn de Hoffmeyer (Bruhn, 1972) hizo el primer intento de afrontar este estudio dentro del marco mucho más amplio del armamento peninsular desde la Edad del Bronce hasta la Edad Media, y fue este marco el que condicionó, a la fuerza, una perspectiva demasiado influida por las fuentes literarias, basando sus datos arqueológicos casi exclusivamente en los hallazgos de Pamplona, aunque existiera ya por entonces la mayoría del material de que hoy disponemos. Al carecer de un contexto arqueológico amplio, este trabajo nos es de poca ayuda ahora.

Desde entonces sólo ha llegado hasta nosotros otro trabajo genérico al respecto, éste de Ardanaz, Rascón y Sánchez (Ardanaz et alii, 1998), que constituye el hasta ahora más completo catálogo de armas visigodas de la Península. Aún reuniendo todos los hallazgos de este tipo hasta la fecha, el estudio se encuentra con vacíos arqueológicos que hay que suplir mediante la comparación con otros ejércitos germánicos, incluido el de la baja época romana.

Hoy en día el panorama no ha variado mucho, y sigue resultando una tarea harto complicada el presentar una panoplia coherente para esta época teniendo en cuenta el largo período de ocupación visigoda y las múltiples variables regionales que se van intuyendo poco a poco.

No es el objeto de nuestro trabajo el intentar recomponer una panoplia «clásica» visigoda, aunque sí intentaremos esbozar al menos unas pinceladas de lo que podía haber sido la panoplia visigoda en la zona del noreste peninsular a finales del siglo VII en transición al VIII para tratar de aportar un poco de luz al, muy oscuro todavía, tema del armamento visigodo.

La mayor traba con que se encuentra el estudio de las armas visigodas resulta en gran medida de las publicaciones que se corresponden a las excavaciones en yacimientos de esta época, en su mayoría necrópolis, realizadas casi exclusivamente durante la primera mitad del siglo XX, teniendo en cuenta las deficiencias de la metodología arqueológica de la época y el abuso de las fuentes escritas (Ardanaz et alii, 1998: 411), así como de las ideas preconcebidas que presentan al visigodo como a un guerrero infatigable ${ }^{1}$ que, por desgracia, no acostumbra a enterrarse junto con sus armas ${ }^{2}$.

Se tiende además a sobrevalorar los elementos ornamentales o artísticos, dejando de lado materiales férricos demasiado oxidados o incompletos. En el caso concreto de las armas, priman las piezas simbólicas o de clase alta como las espadas por encima de las otras.

Esta situación se agrava con la falta de análisis antropológicos y arqueológicos precisos en la mayoría de las necrópolis meseteñas o norpeninsulares, lo cual no permite discernir hasta qué punto los ajuares rescatados pertenecen a individuos de origen germánico o bien a personajes autóctonos hispanorromanos, con el problema añadido de su filiación cronológica y las diferencias de asimilación cultural que corresponden a una u otra época ${ }^{3}$.

1 El conflicto continuo (Pérez, 1989: 136,138) y las repetitivas conspiraciones contra el poder real a consecuencia de la feudalización del ejército provoca la sensación de belicosidad que se suele asimilar al pueblo germánico agravando la idea de su teórica «barbarie».

2 Muchos enterramientos germánicos no tienen en su ajuar armas de gran calidad por lo costosas que resultan como para desecharlas en la tumba. En este particular, juega un papel fundamental la percepción que tenga cada pueblo del mundo de ultratumba (Lebedynsky, 2001: 23-27).

3 Distinguiendo (Palol, 1956) contextos «hispanovisigodos» de los propiamente visigodos, característicos de la etapa anterior al siglo VI. La ley de Wamba (Pérez, 1989: 162) obligaba ya a gran parte de la población a nutrir los ejércitos. 
Otras publicaciones más recientes que incluyen una gran muestra armamentística de esta época (Azkarate, 1998) aún no han visto la luz ${ }^{4}$ bien no se ajustan con exactitud al repertorio formal que ofrecen otras zonas de la Península como la del noreste catalán, puesto que la variedad tipológica o incluso la influencia cultural de las armas parece diferir según la región geográfica en que se encuentran.

Otro de los problemas que hay que afrontar es el de la interpretación de algunas armas u otros objetos complementarios de la panoplia, ya sea como tales o bien como útiles. Éste es un problema clásico en lo que a equipamiento militar se refiere, sobretodo siempre que hablemos de ejércitos con una organización militar poco estandarizada o mal conocida, es decir la práctica totalidad de los ejércitos de la antigüedad exceptuando al romano altoimperial.

Uno de los grandes afectados entorno a este problema es el cuchillo. Cuando hablamos de cuchillo y no de puñal, es lógico pensar que no se trata de una arma, a excepción de ocasiones muy puntuales. Sin embargo, especialmente en ámbito visigodo y en general en todos los pueblos germánicos en los que la aparición de un cuchillo entre la panoplia de un guerrero es muy frecuente (Lebedynsky, 2001: 144-149), hemos de pensar en el cuchillo como un elemento complementario (un útil) del equipo de un guerrero, sin deshechar por supuesto su uso en ámbito doméstico. El cuchillo puede ser muy útil para cortar correas, cuerdas, para comer o para cualquier otra cosa. Lo más probable es que se usara al modo en que nuestros padres o abuelos usaban la navaja.

Otro de los objetos polémicos en este sentido es el hacha (Salin, 1957: 23 y ss.). Otra vez se trata, según el tipo del que hablemos, de un objeto abundante entre las armas de los guerreros germánicos. Su uso, especialmente como arma arrojadiza, está muy bien documentado entre los francos, llegando a interpretarse como armas «nacionales» de estos pueblos (Ardanaz et alii, 1998: 435). Otro tipo de hacha más pesada es más asimilable a un útil, aunque su uso como arma en casos de emergencia no se puede descartar.

El problema de identificación se hace extensible a las armas de asta, tanto las arrojadizas (tipo jabalina) como las de cuerpo a cuerpo (lanzas de mano) o incluso a las armas de proyectiles (arcos, hondas...). Todas ellas pueden usarse para la caza. Sin embargo, hay que pensar aquí en su uso como armas militares; es decir, que puedan ser usadas en un combate contra otros hombres.

Como vemos, si llevamos a su máxima expresión este doble uso del armamento, sólo la espada $^{5}$ y el escudo son armas indiscutibles, así que hay que tener en cuenta el contexto arqueológico de los hallazgos como factor indicativo para discernir cuál podría ser su uso principal o con qué finalidad fue concebida el arma/útil por su fabricante.

En este sentido, es básico entender que el armamento y el equipamiento militar que presentamos aquí proviene de dos plazas militares: un poblado fortificado construido con la finalidad de controlar el acceso a los Pirineos (Hernández, 2001: 132), el caso de Puig Rom en Roses, y un edificio militar preparado para contener una guarnición limitada de soldados que controlan el paso de la antigua Via Augusta en St. Julià de Ramis.(VV. AA., en prep.)

Debido a este contexto, no hay que caer en la tentación de minusvalorar el uso de armas (Palol, 1952a: 172) ${ }^{6}$ en favor de útiles domésticos o utensilios agrícolas, sobretodo si por sus características formales responden más a prototipos de uso militar (como en el caso de las franciscas del que hablaremos más adelante).

\footnotetext{
4 A la espera del vol. 2 con las conclusiones, aunque este no es un yacimiento propiamente visigodo.

5 Es este uno de los factores que hace de esta arma un objeto simbólico de gran valor que se distingue del resto de las armas más multifuncionales.

6 Esto puede dar lugar a interpretaciones confusas (VV. AA., 1999: 158): «...si bé el poblament humà fou sobretot de pagesos, ramaders i pescadors, dels quals ha arribat l'utillatge i objectes d'ús personal, sense, pràcticament, cap element militar com poden ser les armes». Habría que desechar definitivamente este tipo de ideas que contraponen la actividad militar a la agrícola, especialmente sabiendo que en las guarniciones estas actividades se compaginaban (Pérez, 1989: 153).
} 
Por tanto, trataremos el siguiente inventario como armamento u objetos de uso militar sin descartar su posible uso secundario doméstico o venatorio, tratando de discernir en cada caso cuál fuere su utilidad principal.

Antes de proceder a la descripción de los materiales hay que hacer un pequeño inciso en lo que refiere a aquellos procedentes del castellum de St. Julià de Ramis: muchos de los materiales hallados (VV. AA., en prep.) en el interior del edificio del castellum parece ser que estaban almacenados sin haber sido usados nunca, como en depósito. En lo que refiere a nuestro estudio, esto se manifiesta especialmente en el caso de las manillas de escudo y una pieza de bocado de caballo, aunque hay que decir que este hecho se constata también en otro tipo de materiales de temática no-militar.

\section{DESCRIPCIÓN DE LAS PIEZAS}

\section{1. Cuchillos y puñales}

Los cuchillos visigodos (y en realidad los cuchillos germánicos en general) se caracterizan por tener la espiga centrada respecto al eje de simetria de la pieza, en contraste con el tipo habitual de la Península en época tardorromana, cuya espiga de enmangue suele prolongar el lado romo de la hoja (Ardanaz et alii, 1998: 444).

Hemos recogido entre los materiales de Sant Julià de Ramis y Puig Rom un total de diez cuchillos y un posible puñal que podemos clasificar en tres tipos básicos con algún elemento aislado.

-TIPO I (Fig. 2, 1-2): El primer tipo de cuchillo que hemos documentado es de aspecto sencillo, de hoja pequeña (de hecho debía haber tenido el mismo tamaño que la empuñadura una vez unidas las cachas de madera a la espiga) con la punta centrada y no ajustada al lado romo, de modo que la sección de la hoja es triangular y de un solo corte en sus dos tercios proximales mientras que tiene doble corte en el tercio distal. La espiga de enmangue esta centrada respecto la punta. La hoja es realmente estrecha, y el tránsito de esta hacia la espiga es más abrupto en el lado romo que en el cortante.

Tenemos dos ejemplos de este tipo; los dos procedentes de Sant Julià de Ramis.

-TIPO II (Fig. 2, 3-7): El siguiente tipo de cuchillo es el más abundante. Sus características principales serían el perfil curvo del lado cortante de la hoja en contraste con su lado romo, completamente recto. Esto y su mayor tamaño lo distingue claramente de los ejemplares del tipo I. El aspecto de esta hoja lo acerca al de las hojas de las tijeras de mango en «U», tan abundantes en contextos visigodos (en Puig Rom hay ejemplos a decenas); aunque se diferencia de estas por la espiga centrada (sin prolongar el lado romo), al igual que el tipo 1. La hoja es de sección triangular y el tránsito hacia la espiga suele ser bastante sinuoso.

Disponemos de 5 ejemplares del tipo II, tres de ellos de St. Julià de Ramis y dos de Puig Rom.

-TIPO III (Fig. 3, 8-9): El tercer tipo es muy similar al tipo I, con la espiga centrada, la punta situada en mitad del eje de simetria de la hoja, y un solo corte con sección triangular. Sin embargo, y a diferencia del tipo citado, la forma de la hoja es más ancha, especialmente en el centro, y su aspecto es menos frágil. La transición a la hoja desde la espiga es bastante suave hacia el lado cortante.

Hay dos ejemplos de este tipo de cuchillo, ambos procedentes de St. Julià de Ramis. 


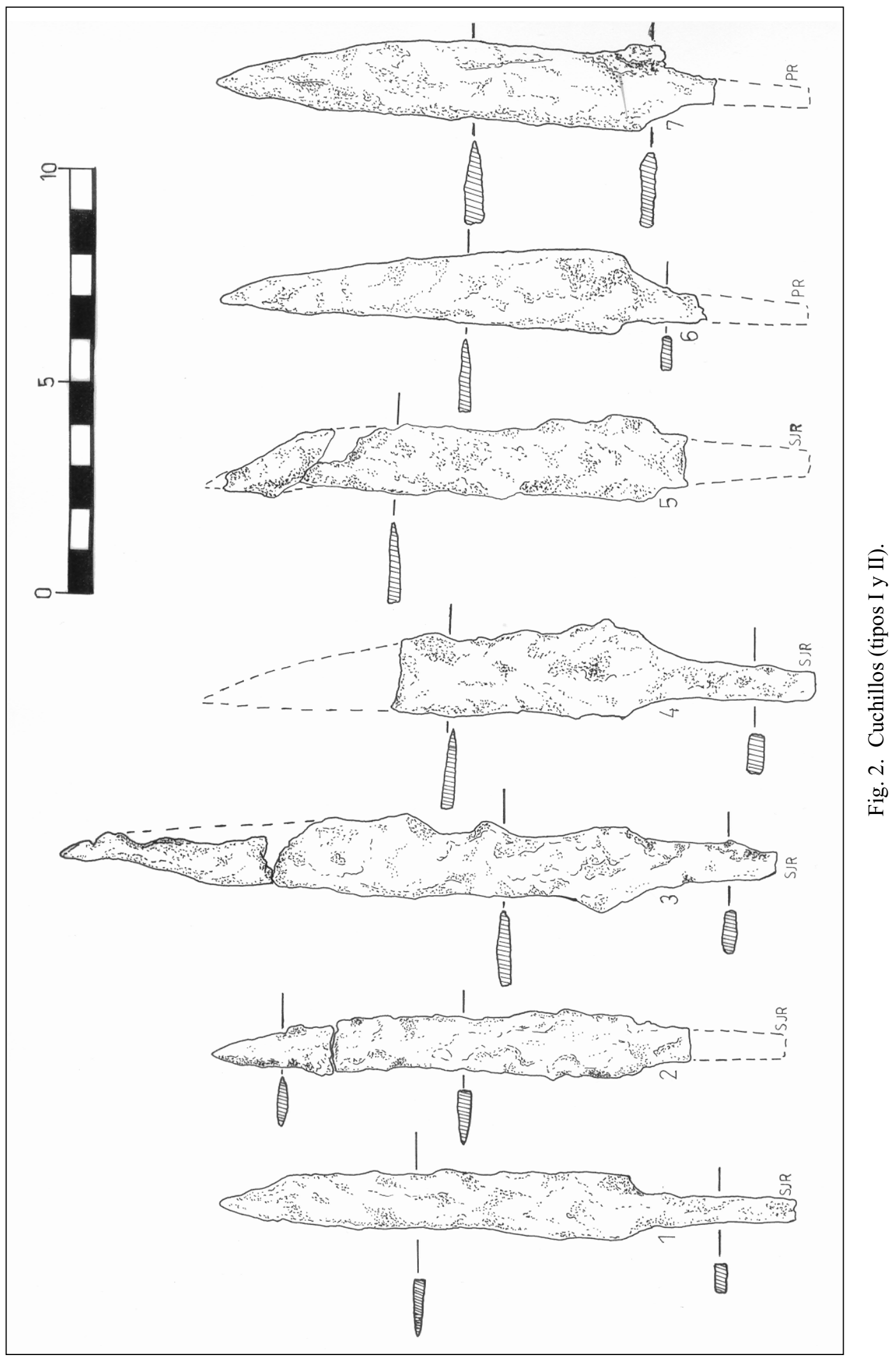




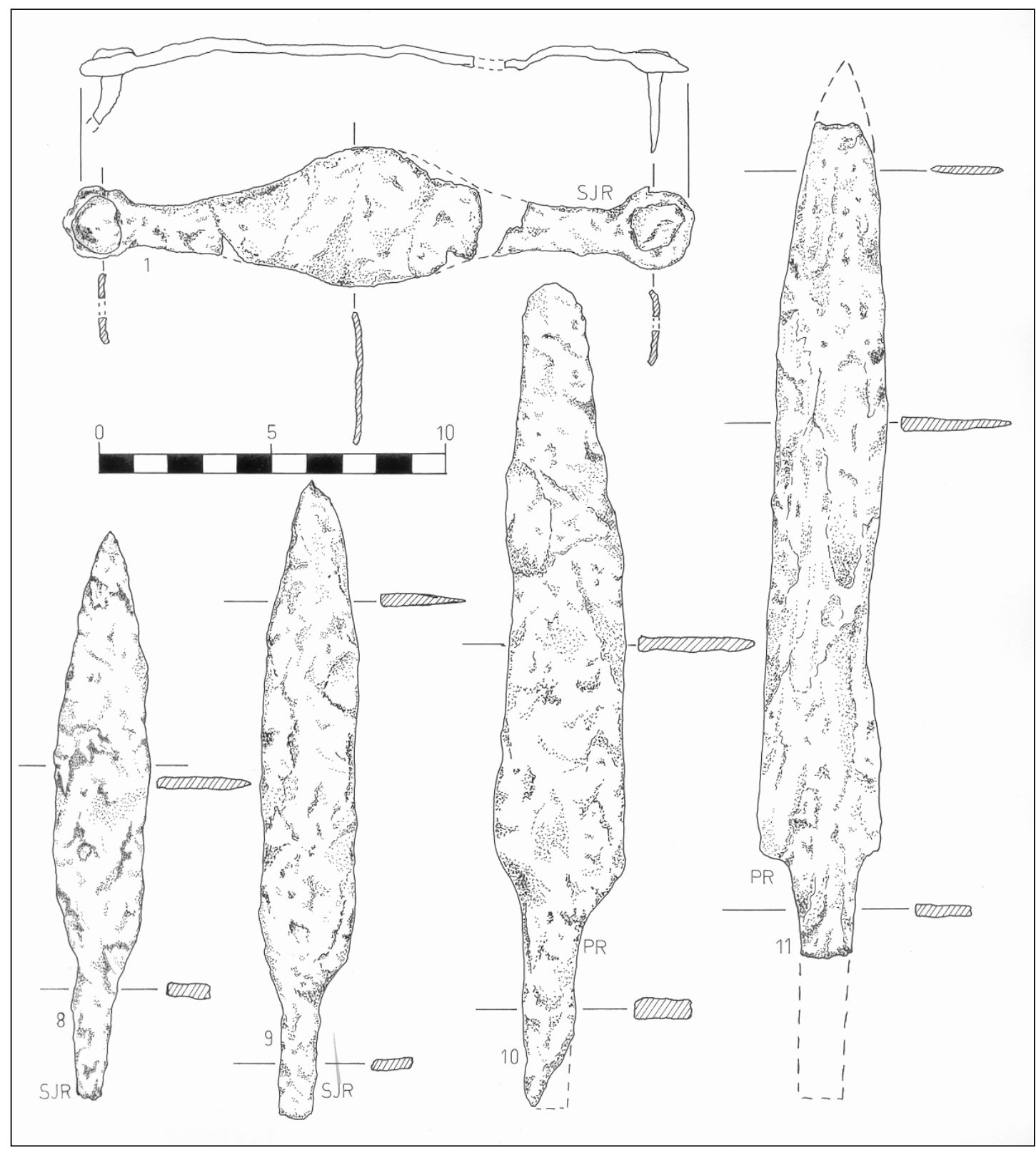

Fig. 3. Cuchillos (8-10), sax? (11) y manilla de escudo del tipo I (1).

-Un tipo aislado de cuchillo muy diferente a los tres anteriores lo forma el $n^{\circ} 10$ de nuestro catálogo. Este ejemplar coincide con el resto en el filo único y la espiga centrada, pero quizás se acerque más al tipo II por su hoja curva en el lado cortante y recta en el romo. No obstante, sus grandes dimensiones tanto a lo largo como a lo ancho lo diferencian claramente de este tipo; aunque su rasgo diferencial más evidente es la punta, completamente redondeada y roma. Este hecho da qué pensar en lo que refiere a la funcionalidad de este cuchillo. La falta de punta condiciona su uso a sólo el corte, evitando la herida con la punta, de modo que bien podría tratarse de un cuchillo de cocina o similar, así que aparece aquí sólo de forma testimonial. 
-Otro ejemplar distinto lo constituye PR-11 (Fig. 3,11), de hoja larga con espiga ancha centrada, rota cerca del tránsito con la hoja. La punta, perdida, tiende a centrarse ya en el último tramo de la hoja, y su único lado cortante tiene una ligera curvatura hacia el interior que quizás sea fruto de una fractura.

La clasificación de esta pieza en relación a su uso militar no resulta sencilla, puesto que el criterio de distinción entre cuchillo y puñal no queda muy claro en aquellos casos en los que las hojas son de un solo corte: según Ardanaz et al.(Ardanaz et alii, 1998: 443), en el Diccionario de la Real Academia Española de la Lengua, la frontera entre uno y otro tipo se centraría básicamente en su uso o no como $\operatorname{arma}^{7}$ (el cuchillo se usaría con distintos fines mientras que el puñal sería básicamente ofensivo), de modo que la definición no nos es de ayuda en este caso.

Este ejemplar de Puig Rom coincide en sus rasgos con lo que en muchos casos se ha denominado como sax (es decir, una pequeña scramasax); arma esta muy frecuente en el mundo germánico. Puesto que las características de esta variante de puñal-machete no son excesivamente claras debido a la ambigüedad de las citas de las fuentes literarias en que aparece, consideramos que hay que ser cautos a la hora de proponer para nuestro caso una solución definitiva, aunque podríamos por ahora decantarnos por una sax en cuanto a su uso como arma secundaria de un solo corte y sus características generales coincidentes, a pequeña escala, con la scramasax 8 .

La diversidad morfológica en los cuchillos estudiados apunta, como ya hemos adelantado anteriormente, a un uso como herramienta más que como arma ofensiva.

En concreto, este hecho es especialmente evidente en los tipos I, II y III, mientras que PR-11 es el tipo que más podría acercarse a un uso dual.

El hecho conocido de la presencia repetida de cuchillos en muchos enterramientos visigodos (Ardanaz et alii, 1998: 411-412) los define como un útil habitual entre las posesiones personales de un alto porcentage de la población de la época. Sin embargo, la ausencia de estudios antropológicos completos ${ }^{9}$ bloquea la investigación a la hora de asignar estas piezas a guerreros (en tanto que hombres en edad militar, sean estos visigodos o autóctonos), de modo que planteamos aquí agruparlos en nuestro estudio básicamente por sus posibilidades lógicas de aparecer entre los enseres de los guerreros visigodos y por afinidad a panoplias de otros pueblos germánicos (Lebedynsky, 2001: 144-147).

\section{2. Manillas de escudo}

El caso de las manillas de escudo no es menos complejo que el de los cuchillos.

El escudo es la principal arma defensiva de la antigüedad y una de las mejores armas ofensivas, y, por tanto, corriente en la mayoría de las panoplias existentes por ligeras que estas sean. Debería ser habitual, pues, el hallazgo de elementos metálicos como manillas o umbos relacionados con los escudos, aunque no tenemos conocimiento de ninguno en ámbito visigodo (Ardanaz et alii, 1998: 446). La explicación más plausible a este hecho quizás sea por su fabricación en madera como es habitual en otros contextos (incluido en ocasiones el romano) sin descartar la posibilidad de que existan ejemplos visigodos en hierro que no hayan sido interpretados como tales o que hayan sido desechados por estar incompletos o en mal estado.

No obstante, hay otros dos modos, aparte de la fabricación en madera, de montar una manilla: uno sería su fabricación enteriza en hierro, lo cual le daría mayor solidez que la ma-

\footnotetext{
7 Palol (Palol, 1952a:178) parece considerarlo más bien un puñal, si es que se refiere a esta pieza.

8 «Existían también sax más pequeñas, incluso de 20 cms., utilizadas en el combate tanto como en la vida diaria» (Contamine, 1984: 228)

9 Véase lo expuesto con anterioridad.
} 
dera pero también más peso; otro consistiría en la cobertura de una manilla de madera con una placa de hierro como forro o protección, del mismo modo que debía hacerse con los umbos. De esta última variedad de manilla tenemos buenos ejemplos en el registro arqueológico de otros pueblos germánicos (Schulze-Dörrlamm, 1985: 521-535), y es el modelo que proponemos para las de Sant Julià de Ramis.

Aunque ya hemos apuntado antes que no disponemos de ejemplos para el mundo visigodo, sí sabemos que el tipo más exitoso de escudo en la Europa occidental era el tipo circular con umbo semiesférico (Contamine, 1984: 228, entre otros), de modo que hay que pensar en este tipo para el caso que nos atañe. Sin embargo, tal vacío de datos para la Península dificulta enormemente la reconstrucción de estas armas defensivas y la identificación de sus elementos ${ }^{10}$, problema que se hace patente incluso en los tipos que presentamos aquí. La interpretación que proponemos (a modo de hipótesis) de estas piezas como manillas de escudo, puede ofrecer dudas que sólo se verán disipadas en el futuro a la luz de nuevos datos en conjuntos más claros.

De un total de cinco manillas, todas ellas de Sant Julià de Ramis, podemos documentar tres tipos distintos correspondientes, muy probablemente, a tres distintas categorías de usuarios de los mismos:

-TIPO I (Fig. 3, 1): Este tipo se caracteriza por sus pequeñas dimensiones y por el hecho de no sobresalir su empuñadura del cuerpo del escudo a diferencia de los otros dos tipos. Los extremos de las aletas de suspensión están redondeados entorno a los clavos, detalle que se repite en el tipo II, y la zona de empuñadura se ensancha hacia el centro de simetría. El grueso de la placa de hierro es mínimo, lo cual subraya su uso como placado de un cuerpo de manilla de madera.

El ejemplar conserva ambos clavos de sujeción, cosa que nos permite especular con el grueso del escudo, que podría situarse entorno a $1 \mathrm{~cm}$. Este dato junto con su pequeña longitud parece indicar que se trate de una manilla de escudo para caballería

-TIPO II (Fig. 4, 2-3): El segundo tipo de manilla es mucho más largo y estilizado. Sus aletas acaban con los extremos redondeados, y el centro de la pieza, correspondiente a la empuñadura, sobresale del cuerpo del escudo para su mejor sujeción. Igual que el tipo I, la zona del centro es más ancha que los laterales.

En ninguno de los dos casos documentados de este tipo se conserva clavo alguno que pueda ayudar a establecer un balance teórico del grueso del escudo. Aún así, está claro que en este caso estamos hablando de un escudo mayor pero no excesivamente pesado a juzgar por la estrechez de sus aletas de suspensión.

-TIPO III: (Fig. 4, 4-5) El último tipo de manilla que hemos documentado es mucho más sólido que los anteriores. Sus aletas de suspensión son muy anchas y cortas, y su cuerpo también se abomba hacia afuera como en el tipo II, aunque en este caso la empuñadura es más ancha y más abrupta en su tránsito con las aletas. Las puntas de dichas aletas no son redondeadas como en los anteriores tipos.

Uno de los dos ejemplares de este tipo conserva un largo clavo que parece indicar que fue fabricado para sostener un escudo muy pesado, de un grueso que podría rondar los 2 cms. Aunque el aspecto sólido de este tipo parece confirmar este hecho, creemos que el clavo, por razones que explicamos más abajo, debería haber sido doblado en ángulo para remacharlo [al modo, por ejemplo, de algunos umbos centroeuropeos (Schulze-Dörrlamm, 1985: 530, fig. 19,3)], en un cuerpo de escudo algo más delgado.

\footnotetext{
10 En ocasiones se han llegado a confundir incluso con grandes grapas de hierro (Fernández y Pérez, 1931)
} 


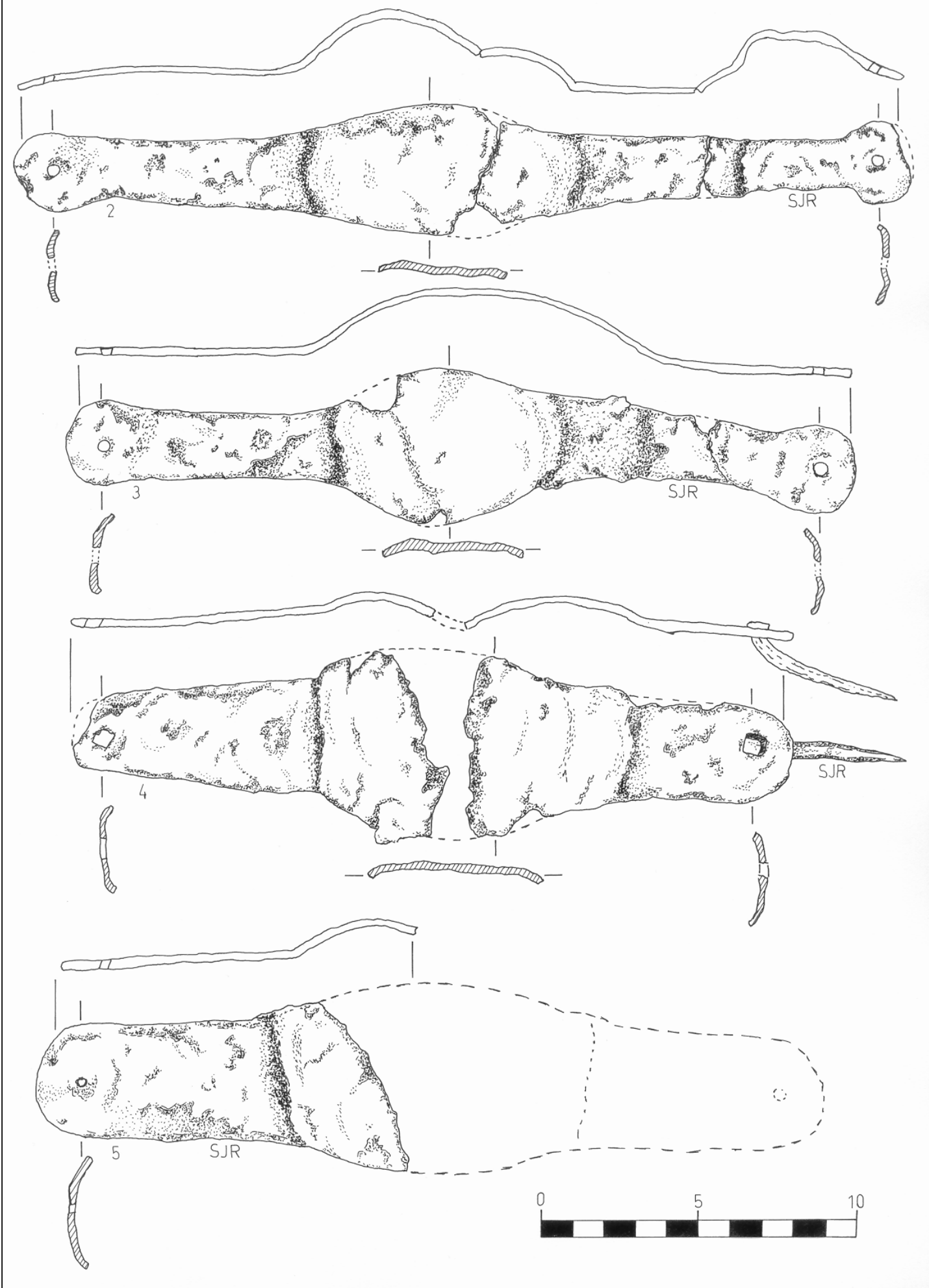

Fig. 4. Manillas de escudo (tipos II y III). 
En resumen, podemos hablar de tres tipos muy distintos de manillas de escudo muy posiblemente correspondientes a tres categorías de guerrero diferente: el tipo I, ligero y pequeño, para caballería; el tipo II, grande y no excesivamente pesado, podría asignarse a infantería ligera; y el tipo III, por su solidez, sería más propio de una infantería pesada.

El hecho que los tipos II y III, que son los más grandes, sobresalgan por su empuñadura los hace más manejables y evita que el umbo tenga que ser muy profundo, especialmente si el cuerpo de madera del escudo es convexo.

Un aspecto a considerar es el hecho que muy probablemente ninguna de estas manillas de escudo, que fueron encontradas en el mismo ámbito, fuera utilizada nunca (o no llegó a ser montada en escudo alguno). Hay varios motivos que apuntan en esta dirección:

En primer lugar, no aparece ningún otro elemento metálico perteneciente a escudo (debería haber algún umbo, que es más normal que se fabrique en hierro para proteger el umbo de madera). Además, las placas aparecieron, concentradas en una estancia bajo los escombros del suelo del piso superior con formas muy deformadas y dobladas, de manera que no parece que estuvieran fijadas a ningún elemento sólido. Hay agujeros para los clavos de sujeción que no tienen clavo y que, como el caso de SJR-5, no parece que nunca hayan sido atravesados por uno, puesto que son muy pequeños. Cuando estos aparecen, como ya hemos indicado antes en el caso de SJR-4, no están remachados o rematados.

Otro indicador del hecho que nunca fueron usados es la anchura de su empuñadura. Normalmente, las empuñaduras de los escudos suelen ser más estrechas para facilitar su manejo (Schulze-Dörrlamm, 1985: 521-535), y en el caso de las manillas placadas en hierro, una vez construido el cuerpo de madera de la manilla más o menos ajustado a la mano del portador, se debe torcer el centro de la placa, que es la parte más ancha, para abrazar el cuerpo de madera. Esto da mayor solidez a la empuñadura, además de evitar que las aristas de hierro corten la mano del portador cuando el escudo sea golpeado.

Las longitudes variables (incluso en una misma pieza) de las aletas y el hecho de que la parte más ancha de la placa no se ajuste con exactitud a la parte sobresaliente de la empuñadura parecen sugerir, además, una fabricación poco cuidada como la que suele caracterizar a las producciones en masa (Sim, 1994).

A todo esto habría que añadir que en Sant Julià de Ramis hay otros grupos de útiles que nada tienen que ver con las armas (VV. AA., en prep.) que también parecen no haber sido usados nunca. Este hecho nos ha hecho pensar que se trate de depósitos para recambios.

\section{3. Hachas}

Hay dos tipos de hacha que nada tienen que ver entre sí entre los materiales de Sant Julià de Ramis y Puig Rom. El problema del hacha es algo parecido al de los cuchillos, en tanto que son de difícil clasificación como armas o útiles. Cualquier hacha puede ser usada para los dos fines, pero hay que tener en cuenta que se trata de un elemento que en determinadas culturas no puede ser usado como arma quizás por cuestiones simbólicas o ideológicas, pero que es sin embargo muy frecuente en la panoplia germánica.

-TIPO I (FRANCISCAS) (Fig. 5): Hemos definido este tipo como francisca por su evidente parecido con estas armas bastante comunes en el mundo franco aunque también presentes en contexto peninsular (Azkarate, 1998). Ya Isidoro de Sevilla documentaba su uso entre los visigodos (Lebedynsky, 2001: 87-88). Se trata de una arma arrojadiza (y por ello no demasiado grande), con un talón posterior que actúa como contrapeso y como refuerzo del mango. Este mango debe ser corto (Lebedynsky, 2001: 171), y el extremo proximal del corte suele ser más largo para facilitar su rotación en el lanzamiento. 


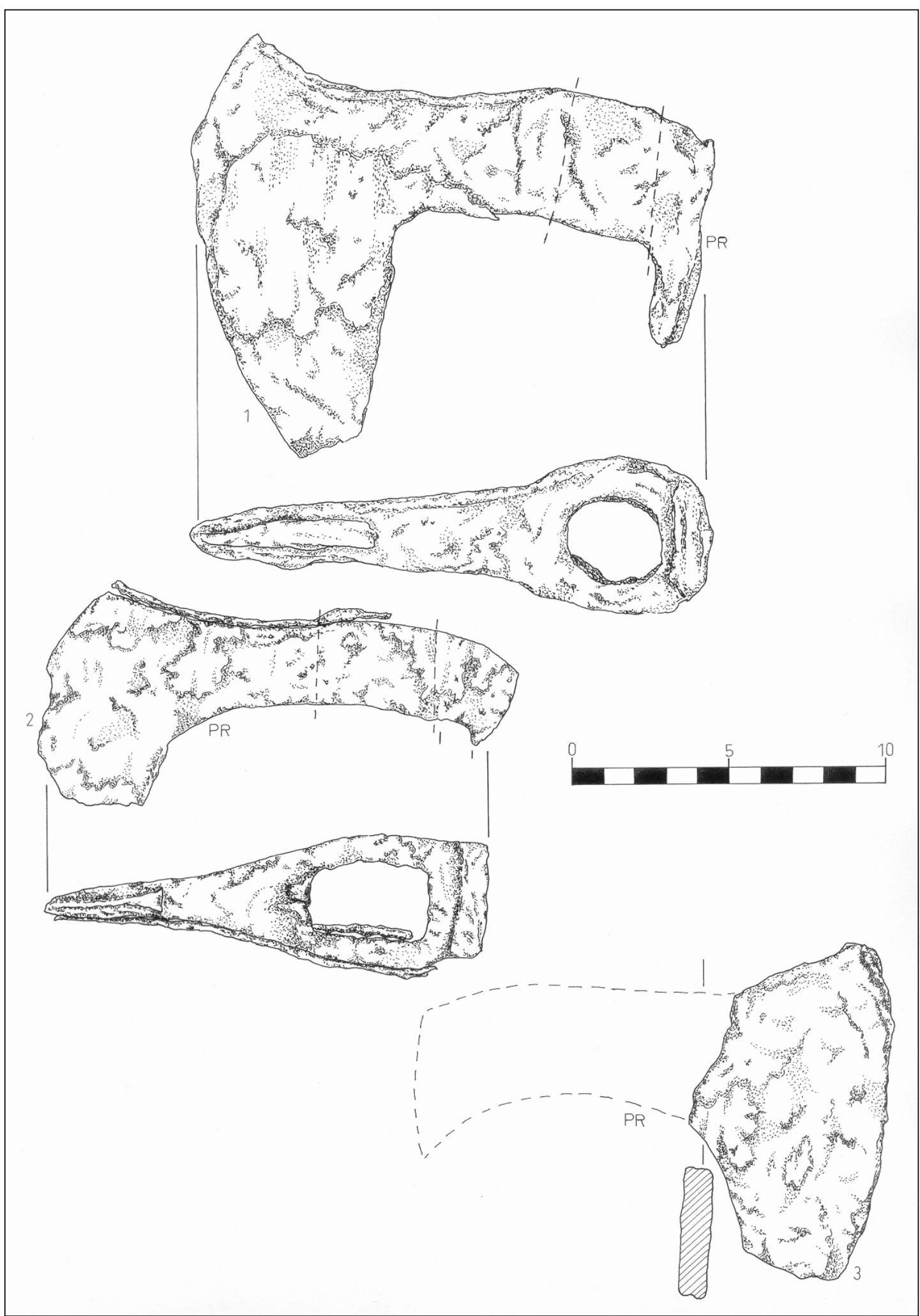

Fig. 5. Hachas arrojadizas (tipo I). 


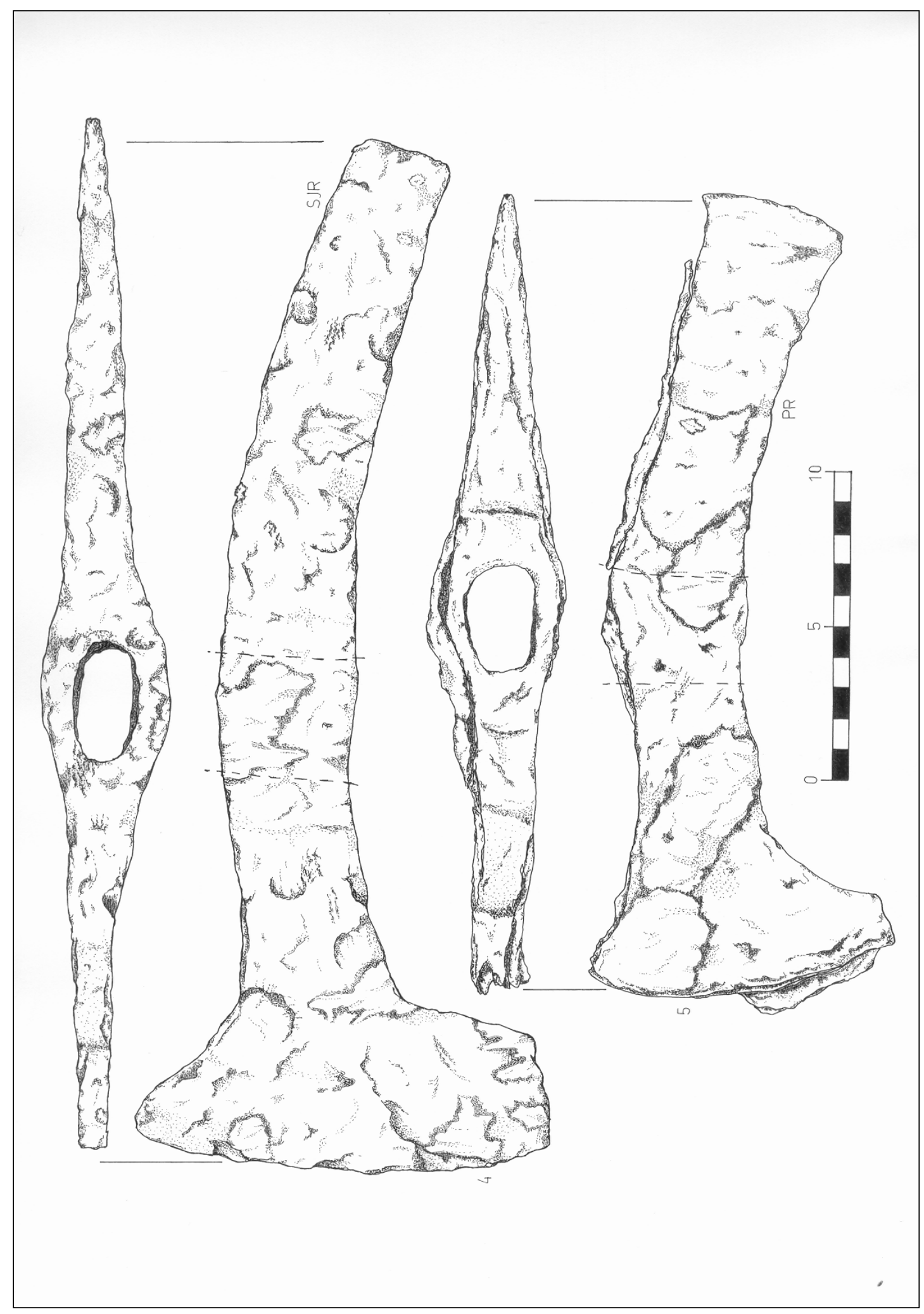

Fig. 6. Hachas de doble corte (tipo II). 
Hay dos hachas arrojadizas de este tipo en Puig Rom y ninguna en Sant Julià de Ramis. PR-3 también podría ser una de ellas, pero sólo conserva el corte, de modo que es imposible aclarar si corresponde a una francisca. El caso de PR-1 contiene todas características de una de estas armas, aunque en su momento fuera clasificada como útil agrícola (Palol, 1952a: 172).

-TIPO II (Fig. 6): Hemos agrupado en este tipo dos hachas dobles de iguales características que únicamente se diferencian en sus medidas.

Este tipo se caracteriza por un doble corte; el principal de ellos pronunciado en la su extremo proximal de forma muy abrupta y el secundario simple como el de un pico de corte vertical, sin ensancharse al final. Se trata de hachas muy pesadas que deben ser sostenidas a dos manos con un mango largo (como el de un pico), y sin duda hay que entenderlas como útiles por su similitud con las dolabra romanas (Bishop, Coulston, 1993: 104) ${ }^{11}$.

Hay que concluir, pues, que sólo el tipo I de hacha se puede catalogar como arma, y que en todo caso hay que asignar su uso principalmente con efecto a media distancia, aunque no se puede descartar su uso cuerpo a cuerpo en caso de necesidad (especialmente los ejemplares más grandes como PR-1) (Lebedynsky, 2001: 171; Salin, 1957: 40). No hay que olvidar que esta es una arma arrojadiza pesada, muy frecuente en contextos merovingios, con los que parece clara una relación con los asentamientos visigodos de la zona del noreste peninsular, tal y como veremos más adelante.

\section{4. Armas de asta.}

La gran variabilidad de las armas de asta se manifiesta en este apartado de forma evidente, pues parece ser que cada una de ellas podría constituir por sí solo un tipo aparte, y que sólo algunas tienen paralelos parecidos en otros lugares de la península en contextos de la misma cronología. No obstante, cuanto más se investiga específicamente en este ámbito, más se evidencia que en general hay patrones de fabricación de puntas de lanza en determinados contextos culturales, así que no hay que caer en el error de pensar que hay una absoluta anarquía a la hora de fabricar estas armas.

Las diferencias en las distintas morfologías de las puntas hay que entenderlas por la gran variedad de efectos que pueden producir, según sea si prima la intención de cortar o perforar (desgarramiento y perforación) o si se trata de que el arma sea ligera y pueda lanzarse, ya sea sólida, resistente o flexible.

Uno de los problemas más clásicos que hay que afrontar aquí es la dificultad de la transición entre jabalinas o lanzas de mano (especialmente si la jabalina es pesada), y quizás sea éste uno de los aspectos más frágiles del estudio de este tipo de armas.

\section{- Puntas de jabalina: (Fig. 7)}

Hemos hallado dos puntas de jabalina de características muy distintas entre sí:

La primera (PR-1) es de aspecto simple, de cuello largo y hoja romboidal de sección losángica estrecha. El tubo de enmange troncocónico está semiabierto producto de su fabricación. Esta característica suele aparecer en esta época en contextos diversos, y es posible que remita a su fabricación en serie o conjunta con otras piezas de su categoría (Sim, 1994: 2), hecho que puede ser frecuente en la producción de armas arrojadizas de este tipo. El aspecto de esta punta es aerodinámico para su lanzamiento, y la estrechez de la hoja indica que fue concebida para penetrar sin ensanchar demasiado la herida.

11 En la necrópolis de Deza (Taracena, 1926: lam. XVII) aparece una con características análogas excepto por su corte secundario, que es apuntado como el de un pico. 
La otra punta de jabalina, procedente de Sant Julià de Ramis (SJR-2) tiene su origen en las excavaciones realizadas durante los años 1932-1945 por F. Riuró (Burch et alii, 2001), y no conocemos a ciencia cierta su contexto de hallazgo, de modo que no podemos afirmar con rotundidad su origen visigodo ${ }^{12}$. Sin embargo, los paralelos conocidos de este tipo de punta en contextos merovíngios (por ejemplo Lebedynsky 2001: 162) sin que haya piezas similares conocidas en ámbito ibero, indican que muy posiblemente pueda incluirse en este periodo de ocupación del yacimiento.

La punta en cuestión tiene forma de hoja de laurel bastante ancha y sección losángica, cuello muy largo y cubo corto también semiabierto como el de PR-1. El tránsito entre cuello y hoja es muy sinuoso, al contrario que el del caso anterior.

Se trata de una hoja de jabalina agresiva, con gran poder de desgarramiento y más pesada que la anterior. Su estilo de hoja y cuello largo recuerda algunos ejemplares que han sido catalogados en contextos merovíngios como framea, (Salin, 1957; chap. XXV, 13-14) aunque las características de este tipo de jabalina son poco claras y responden a prototipos literario que difícilmente pueden asignarse a materiales arqueológicos.

En todo caso, podemos distinguir claramente que, siendo ambas armas concebidas para ser arrojadas a cierta distancia, en el primer caso podemos hablar de una jabalina ligera (posiblemente usada con otros ejemplares similares) mientras que la punta SJR-2 sería más bien una jabalina semipesada, de mayor impacto pero efectiva solo a distancia más corta.

\section{- Puntas de lanza de mano: (Fig. 8; Fig. 9, 6-7)}

La gran variedad morfológica de las puntas de lanza se hace especialmente patente entre las lanzas de mano, puesto que de los cinco ejemplares que proceden de estos dos yacimientos no hay ninguno que se repita dos veces:

-PR-3: Es una punta muy alargada pensada para la penetración profunda sin encontrar resistencia lateral; muy efectiva empuñada. De cuello corto con cubo de enmangue largo y fino. En el extremo proximal del cubo, el cuello se estrecha y se une con la hoja a través de una espalda levantada muy frecuente en este periodo cronológico (Azkarate, 1998) y que se repite en ejemplares similares en la península (Tañine, Aldaieta...).

-PR-4: De hoja ancha y larga. Se trata de un ejemplar de punta grande y pesada, de sección romboidal y hoja lanceolada, sin nervio y muy flexible. El cuello no muy largo se une con la hoja de forma muy sinuosa y la fractura de la pieza cerca del arranque del cubo de enmangue no permite calcular su longitud total. Sus características, nada habituales en contextos de esta época, la hacen una arma muy efectiva cuerpo a cuerpo incluso en los golpes laterales gracias a la anchura y flexibilidad de su hoja.

-PR-5: Esta gran punta de lanza, de 40cms de largo, contiene una gran hoja de sección romboidal y de forma lanceolada con un tránsito al cuello bastante abrupto que cae desde la hoja en curva. El cuello es la parte más larga, siendo equivalente a la hoja y el cubo juntos. A partir de la parte proximal del cuello, éste se va ensanchando poco a poco hasta conseguir una apertura considerable: la parte hábil del enmangue tiene 2' $8 \mathrm{cms}$. de diámetro (para entendernos, la parte equivlente a una sarissa macedónica), dato que indica que el arma se utilizaba a dos manos. Sin duda, se trata de una lanza de caballería, muy fuerte y sólida.

-SJR-6: Punta de hoja muy larga y estrecha de sección romboidal. Tiene un nervio central muy grueso y su cuello, muy corto en relación a la hoja, se relaciona con esta a través de

12 Hay que recordar que la montaña de St. Julià de Ramis fue ocupada con anterioridad por un asentamiento ibérico (Burch et alii, 2001). 


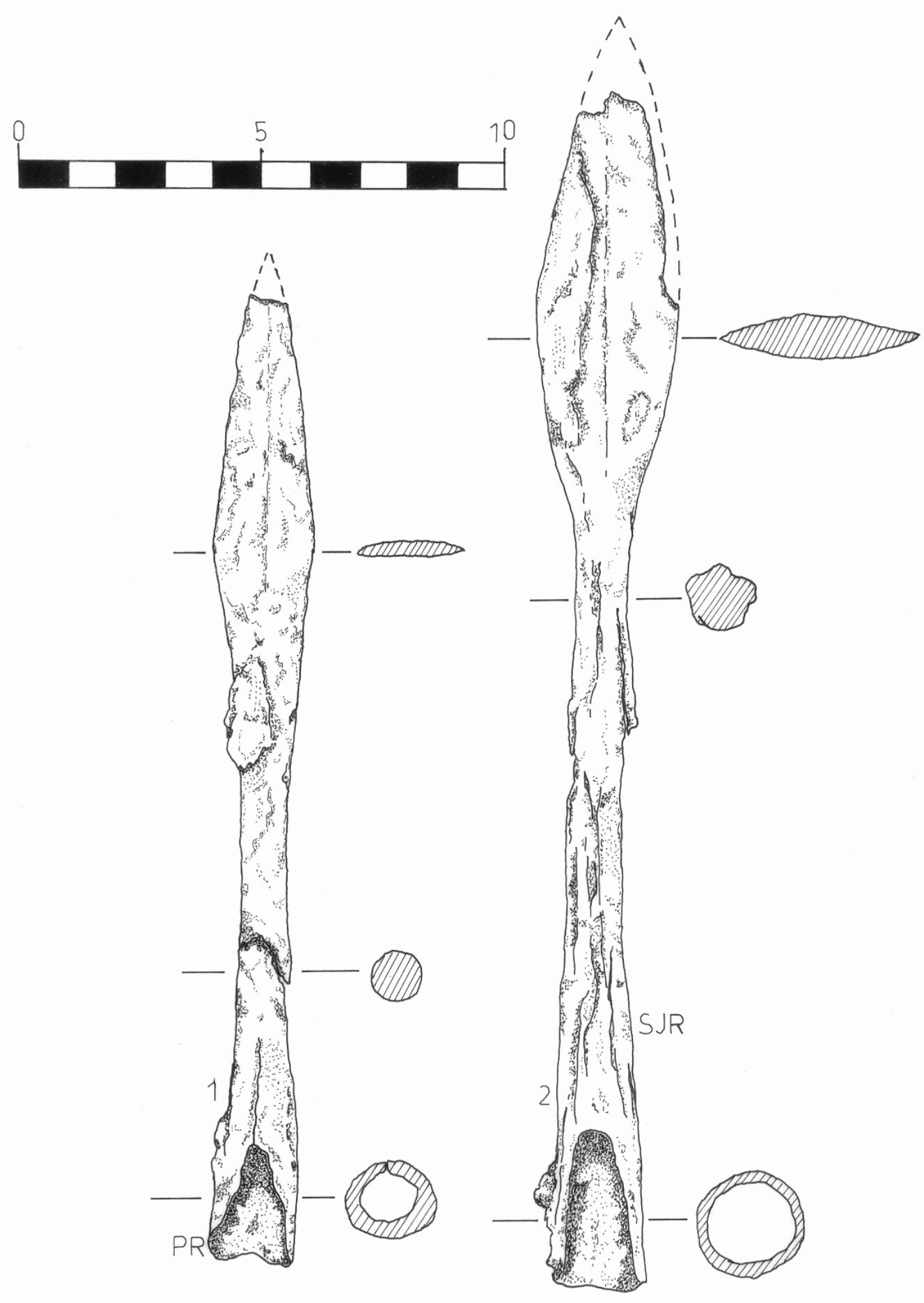

Fig. 7. Armas de asta: jabalinas. 


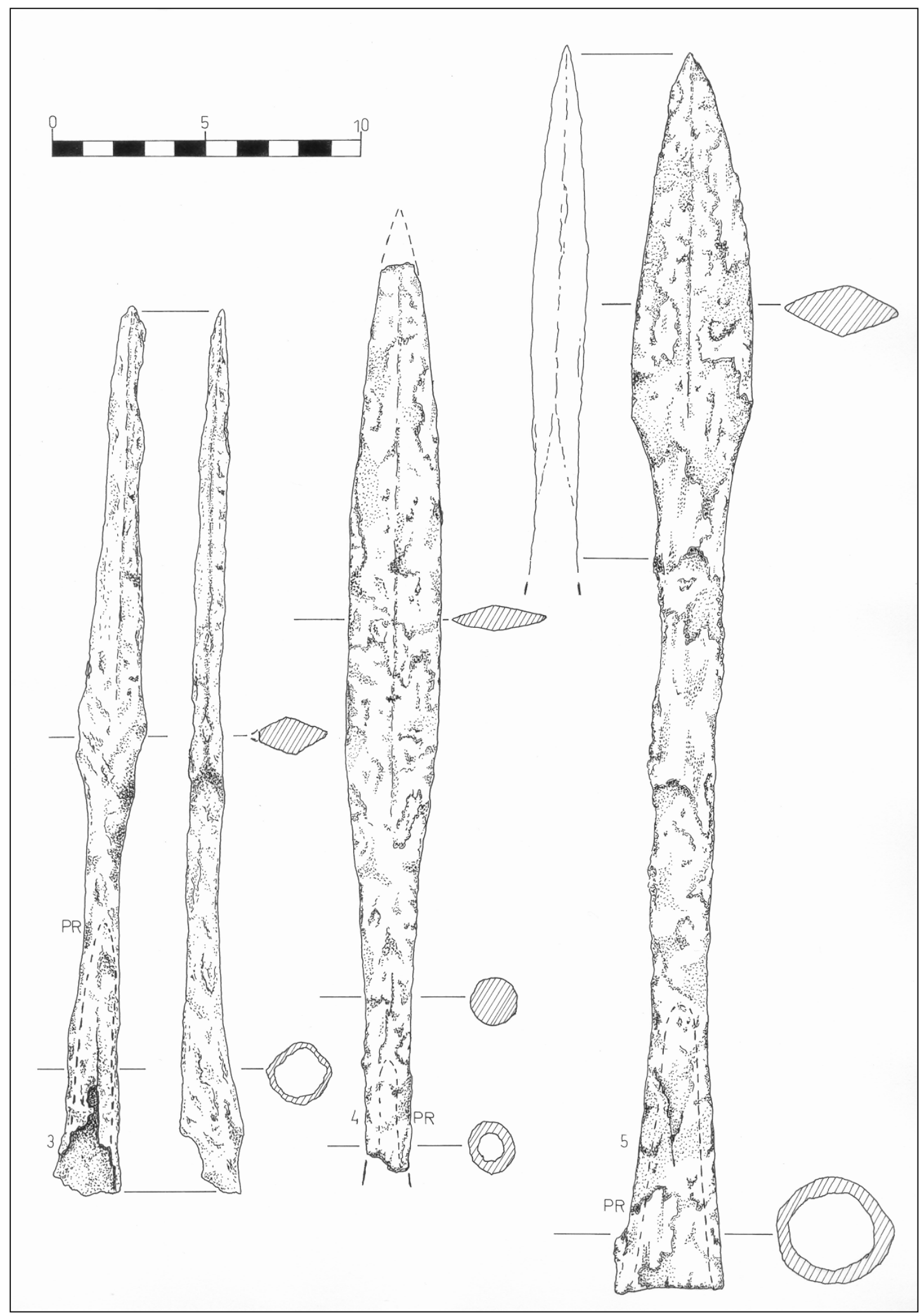

Fig. 8. Armas de asta: puntas de lanza 
un estrangulamiento suave. Las espaldas de la hoja están levantadas, como en el caso de PR3 , con la que parece tener muchos puntos en común a excepción del nervio.

En la parte inferior del cubo de enmangue tiene un pequeño clavo de sujeción al asta. La hoja está deformada y fracturada en uno de sus costados. Este tipo de desgaste es más frecuente en puntas de este tipo, cuyo nervio refuerza su dureza en detrimento de la flexibilidad de la hoja. Es por esto que esta pieza es una arma de choque profundo, pensada para herir de punta, de modo que quizás también se trate de una punta de lanza para caballería, aunque no se pueda descartar su uso a pie.

-SJR-7: Punta de lanza senzilla, de hoja lanceolada de espalda levantada y sección losángica. De cuello corto ligeramente estrangulado al contacto con el cubo troncocónico para el enmangue, que es de fijación simple sin clavo de sujección.

El diámetro de cubo y las medidas y características de la hoja hacen pensar que se trate de una lanza semiligera para infantería, útil sujetada a mano o lanzada si es necesario. Es manejable y equilibrada.

De todo esto se desprende un uso diversificado de las lanzas de mano que incluyen su uso para infantería (desde las más ligeras como SJR-7 o PR-3 teniendo en cuenta sus diferencias formales, a las más pesadas como PR-4) o caballería (SJR-6? y PR-5), siendo todas ellas (a excepción la primera), patrones hasta ahora desconocidos en ámbito visigodo. De todos modos, hay que aclarar que esta diferenciación de formas se debe a la variedad de necesidades que surgen a la hora de plantear el efecto que quiere producir la punta. Cualquiera de estos tipos puede repetirse en otros contextos de esta cronología, puesto que no hay que olvidar que el estudio del armamento visigodo está todavía en una fase muy primeriza.

- Regatones (Fig. 9, 8-9):

El uso de regatones hay que relacionarlo sobretodo con las lanzas de mano, ya que en las jabalinas puede ser devuelta al atacante en su contra, aunque no hay que descartarlos del todo en este tipo de arma puesto que, como hemos visto, la frontera entre una y otra no es siempre muy clara.

-Tenemos tan sólo dos ejemplos de regatones de morfología muy distinta: El primero (PR-8) de sección cuadrada hasta su extremo proximal muy cerca del cubo de enmangue, que aparece fracturado.

El otro ejemplar (SJR-9), tiene también la punta de sección cuadrada pero es muy diferente tanto en su longitud, claramente superior al anterior, como en su cubo de enmangue, que es más claramente troncocónico e iba sujeto al asta mediante dos remaches laterales.

La junta de los dos costados de la lámina que forma el cubo está mal soldada y se abre sensiblemente en su contacto con la punta, hecho éste frecuente en los regatones que no tienen sección circular debido al proceso que debe sufrir en su fabricación.

Del análisis de estas dos piezas podemos afirmar que el tipo de lanza que acompañaba a PR-8 debía ser no demasiado larga pero sí robusta, mientras que la forma de SJR-9 apunta a un arma de características más estilizadas (el ancho de obertura del cubo de enmangue y la longitud así lo indican), del tipo de PR-3 o SJR-6.

\section{5. Armas de proyectiles}

Hemos añadido a nuestro catálogo de forma testimonial una única punta de flecha (PR-1) aparecida en Puig Rom (Fig. 9, 1), puesto que el uso de arcos y flechas está ampliamente 
documentado en las fuentes literarias (Lebedynsky, 2001: 175). Los visigodos eran considerados unos buenos maestros en el uso de arco (Bruhn, 1972: 89), pero aún así, este es el único ejemplar que conocemos para esta época, debiendo ser, a priori, un tipo de material producido en grandes cantidades.

Aunque en el caso de las puntas de flecha es especialmente importante el peso de su uso venatorio, debe quedar claro que aparecen aquí entre las armas por sus vinculaciones ya atestiguadas (Vid. supra) con el ámbito militar visigodo.

\section{6. Elementos ornamentales: hebillas (Fig. 10)}

Uno de los elementos más habituales y conocidos de los visigodos son sus hebillas. Hay hallazgos de hebillas de bronze decoradas en casi todos los yacimientos del siglo VII, y es por ello que son los materiales de esta época que han recibido más atención por parte de los estudiosos (RIPOLL, 1998).

Hemos incluido las hebillas en nuestro estudio sobre equipamiento militar por creer que son elementos que, aunque con seguridad no exclusivos de los guerreros, sí al menos frecuentes entre estos. Hay que constatar que las hebillas decoradas suelen estar presentes en la mayoría de enterramientos con panóplia tanto en contextos visigodos como en los de otros pueblos germánicos (McDowall y McBride, 1996; Joffroy, 1974).

Disponemos de cinco ejemplos de hebilla pertenecientes a las excavaciones realizadas en Sant Julià de Ramis y Puig Rom.

-El tipo más conocido de hebilla visigoda está presente en dos ocasiones: una en Sant Julià de Ramis (SJR-1) y otra en Puig Rom (PR-2).

Se trata de dos placas de hebilla de tipo arriñonado, decoradas, datables del siglo VII a principios del VIII (tipo C de Ripoll (Ripoll, 1998: 136)), y de tradición bizantina. Sólo conservan la placa, mientras que la anilla y la púa se han perdido.

PR-2 ya fue estudiada en su día por Pere de Palol en su conocido trabajo sobre hebillas visigodas (Palol, 1950).

El caso de SJR-1 ${ }^{13}$ es muy parecido aunque más pequeño, y contiene decoración retocada a buril dividida en tres sectores (característica de este tipo): uno con forma arriñonada que invade con su parte central el interior del campo medio, situado en el extremo distal respecto a la anilla; otro central dividido en dos almendras dispuestas longitudinalmente; $y$ un tercero situado en el extremo proximal con forma cuadrangular también con su centro tendiente al campo medio.

El tipo de decoración es difícilmente apreciable a consecuencia de su desgaste, pero hay que apuntar a un posible tema vegetal.

El exterior de la placa resigue con su forma las aristas de los campos ornamentales, en paralelo a éstos y culmina en el extremo distal con un apéndice decorativo también muy habitual en este tipo. El reverso contiene tres hembrillas agujereadas para su sujeción al cuero del cinturón, a diferencia de PR-2 que tiene cuatro.

-SJR-3 es una hebilla de hierro de forma estrecha y alargada con decoración dentada en todo su recorrido externo. La fijación al cinturón de cuero se conseguía a través de remaches de bronce (en origen tres, de los cuales sólo se conserva uno en el extremo distal) que consti-

13 Conviene mencionar la existencia de otra hebilla semejante en Sant Julià de Ramis también con tres hembrillas de sujeción aunque de más calidad en su conjunto (Palol, 1950: fig. 7, 2) que se encuentra en el MAC-Barcelona. 


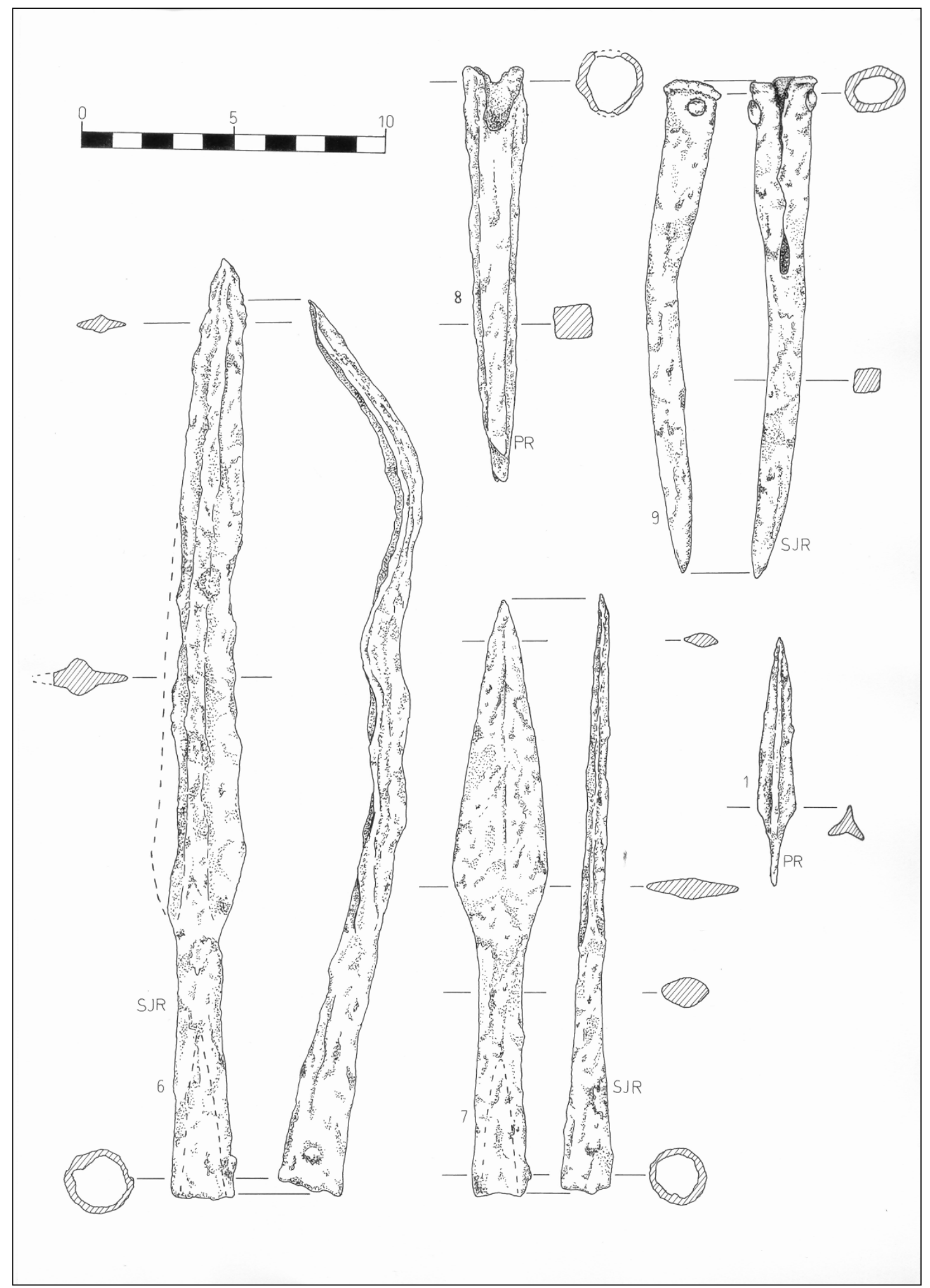

Fig. 9. Armas de asta: puntas de lanza (6-7), «regatones» $(8,9)$. Punta de hacha (1). 


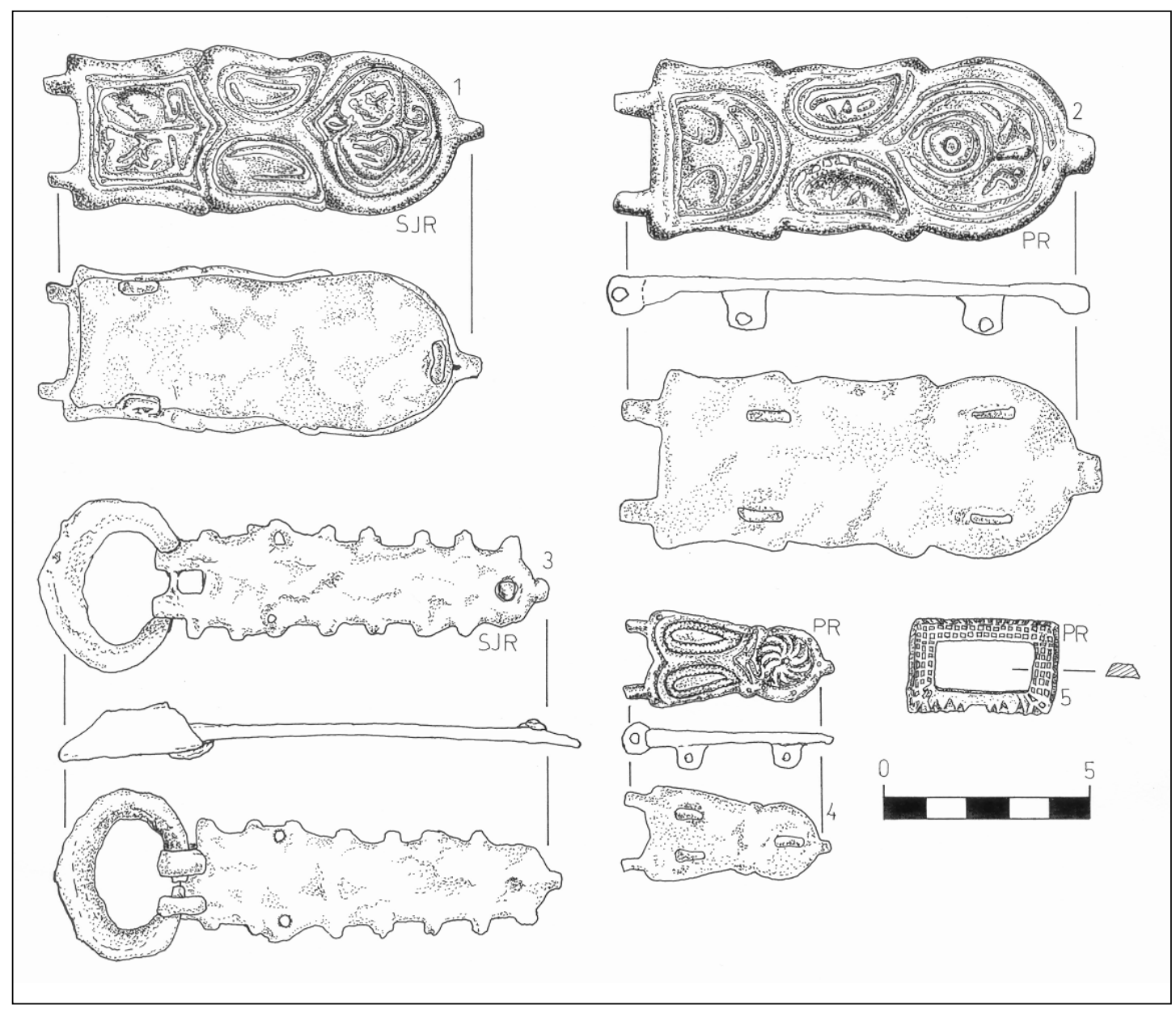

Fig. 10. Hebillas de cinturón.

tuyen la única decoración interna de la pieza, basándose en el contraste de color y brillo entre el bronce y el hierro. La hebilla conserva la placa y la anilla, pero no la púa. Hemos catalogado esta pieza ya con anterioridad (VV. AA., en prep.) como una pieza de orígen o influencia merovíngio, ya que contiene tres características muy típicas de las hebillas francas como son su fabricación en hierro y no en bronce ${ }^{14}$, su fijación a partir de remaches de bronze y no de hembrillas, y su anilla delgada y muy profunda a diferencia de las típicas visigodas más llanas y redondeadas.

No obstante, hay que decir que no es un tipo muy habitual de hebilla, y no conocemos ningún paralelo exacto.

-PR-4 pertenece a otra categoría. Esta hebilla se corresponde con el tipo D de Ripoll para la bética (Ripoll, 1998: 136). Es importante resaltar aquí su uso, puesto que sus pequeñas dimensiones indican que más bien se trata de un tipo de hebilla para correas de suspensión, seguramente para armas, de tipo tahalí.

14 Con excepciones, eso sí, incluso en las hebillas más parecidas a esta (Joffroy, 1974: tombe 35). 
-PR-5 solamente conserva la anilla, de estructura rectangular nada frecuente en ejemplares de placa no-rígida. Nos es totalmente desconocida su decoración a base de cuadrículas.

Lo importante a resaltar en el estudio de las hebillas visigodas para el caso que nos ocupa radica sobretodo en la distinción entre los ejemplares SJR-1, SJR-3, PR-2 (y quizás PR-5), correspondientes a cinturones, frente a PR-4, asociada hipotéticamente a tahalíes para la suspensión de armas tales como espadas o scramasax.

\section{7. Equipamiento para caballería}

- Hebillas de caballería (Fig. 11, 1-8):

En la figura 11 aparecen una serie de hebillas de hierro que por sus características y sus grandes medidas hemos catalogado, de forma totalmente hipotética, como pertenecientes al correaje de caballos para sillas o arneses. No vamos a entrar en la descripción detallada de estas piezas, pero sí apuntaremos que existe una cierta distinción entre los tipos de perfil llano (PR-1, SJR-6, SJR-7), y aquellos (SJR-2, PR-3, PR-4, PR-5) que se caracterizan por su estrechez en el centro. Los tipos más pequeños podrían asignarse a arneses, aunque también cabe la posibilidad que pertenezcan a otro tipo de cierres, como los de bolsas o mochilas.

- Elementos de arnés (Fig. 11, A-C):

Podemos describir, a partir de los hallazgos realizados, dos tipos de bocado de caballo y arnés bien diferenciados y con orígenes, al parecer, muy distintos.

-TIPO I: (PR-A)

Se conserva de este tipo tan solo un fragmento correspondiente a la cama y parte del bocado. El ejemplar consiste en un bocado articulado (véase PR-A') que aparece roto en su mitad interior y que enlaza con la cama a través de una pieza solidaria a esta que deja un espacio en forma de triangulo que luego se alarga en un vástago para bifurcarse y abrazar la correa del arnés. La cama conserva uno de sus remates doblado, de forma ornamental, hacia un lado. El enlace con las riendas se realizaría a través de una anilla simple articulada con la anilla distal del bocado, alargada a este efecto.

El parentesco de este ejemplar con los tipos de tradición oriental (Dietz, 1990: 414 y ss.) es bastante claro, debiéndose su aparición en este contexto a la importancia que fue obteniendo la caballería entre los godos a raíz de su contacto con los pueblos nómadas de las estepas (Lebedynsky, 2001: 93)

-TIPO II: (SJR-B, SJR-C)

El tipo alternativo de arnés de caballo podemos rastrearlo a partir de una pieza del bocado (SJR-B) en forma de vástago con sendas anillas a los extremos. Esta pieza debía articular con una pieza gemela para introducirse en la boca del caballo y enlazar después con arnés y riendas. Para evitar desplazamientos laterales, cerca de la transición con las anillas laterales se insertaba unas ruedas caladas de bronce, de sobras conocidas en contextos visigodos ( $\mathrm{Pa}$ lol, 1952b), que remataban en un enganche trapezoidal para enganchar las correas del arnés. Las riendas se incorporaban al bocado a través de una anilla exenta encadenada a las anillas distales del mismo. Este tipo puede reconstruirse fielmente a partir de hallazgos como el de Toledo (Palol, 1972). 
La anilla de bronce SJR-C muy probablemente se correspondiera a una anilla de sujeción de arnés (frontalera a quijera) que sirviera, juntamente con la rueda calada, para la decoración de los arreos.

A diferencia del tipo I, este tiene su tradición en los ejemplares tardorromanos ya documentados en la Península Ibérica (como el citado de Toledo).

\section{CONCLUSIONES}

De la descripción de todas estas piezas se puede desprender la gran variabilidad que presentan, incluso en una zona tan reducida como la que tratamos, los tipos de armas y elementos del equipo militar del guerrero visigodo.

No hay que olvidar que los ejércitos visigodos de época tardía tenían un carácter claramente feudal y se organizaban a partir de ejércitos privados que dependían de grandes propietarios (incluyendo los eclesiásticos) con obligaciones a nivel de prestación militar para con sus patrones (Pérez, 1989: 174 ). Este hecho estructural condiciona de por sí una panoplia poco homogénea en lo que refiere a la territorialidad: cada ejército privado tenía su propia panoplia (que debía facilitar el patrón ${ }^{15}$ ) y se preocupaba principalmente por la defensa interna de su propio territorio, llegando a causar serios problemas a la monarquía a la hora de movilizarse contra amenazas externas.

Aunque no sabemos con certeza como se relacionaban las dos plazas defensivas que incluyen las piezas que aquí estudiamos, sí podemos pensar que existía algún tipo de vínculo en relación con el control fronterizo al norte, que ya se había mostrado en alguna ocasión como foco de disputas contra los intereses monárquicos. Las piezas militares depositadas en los estratos de abandono de Sant Julià de Ramis y Puig Rom denotan una cierta despreocupación frente a la invasión sarracena, fruto muy probablemente del interés de los propietarios locales por integrarse al nuevo orden sin tener que presentar oposición, esperando conservar sus territorios y olvidando los lugares relacionados con la vieja estructura defensiva visigoda ${ }^{16}$.

En lo que refiere a la panoplia resultante de nuestro estudio, cabe señalar la presencia de la mayoría de elementos que formarían parte de ella, estando presentes las armas ofensivas de corte (puñal, hachas), de asta (jabalinas, lanzas y regatones) y de proyectiles (puntas de flecha); las armas defensivas (escudos representados por sus manillas, o incluso un abrojo en tetraedro de hierro procedente de Puig Rom (Palol, 1952a: 176) pero actualmente ilocalizable) y una amplia variedad de objetos relacionados con el equipamiento militar (desde cuchillos a ornamentos tipo hebilla, pasando por equipo de caballería). No obstante, hay ausencias significativas, puesto que no están representadas ni armas de cuerpo a cuerpo tipo espadas o scramasax ni armamento defensivo pasivo de protección corporal (cotas de malla o escamas, cascos, etc...). La explicación a estas ausencias puede estar en el carácter simbólico de las espadas y el carácter restrictivo (seguramente reservado a una élite militar) de las corazas o cascos metálicos.

Aún así, y pese a la inexistencia en nuestro caso de contextos cerrados con asociaciones de armas, podemos intuir al menos tangencialmente una variedad de objetos que podríamos agrupar en panoplias asignadas a distintos tipos de guerrero, habida cuenta que en los ejércitos germánicos la organización militar respondía a un reflejo de su estructura social (Lebedynsky, 2001: 59):

\footnotetext{
15 De ahí quizás la existencia de recambios como los de Sant Julià de Ramis (Vid. supra).

16 Prueba de esta capacidad de adaptación la constituye la actitud indecisa del obispo Amator de Girona en la revuelta de Paulus (Pérez, 1989: 148, 158).
} 


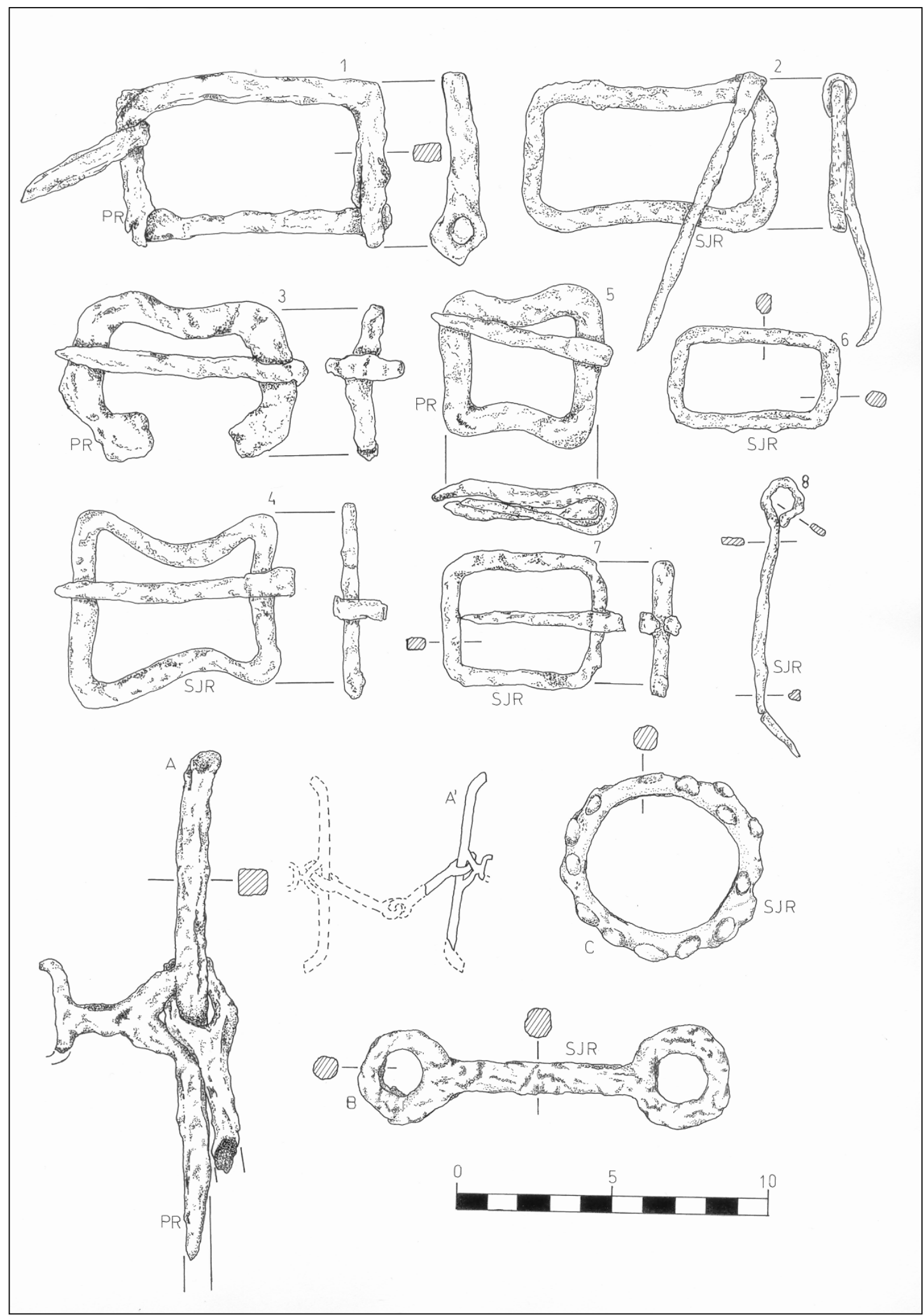

Fig. 11. Equipamiento para caballería: hebillas (1-8) y elementos de bocado (A-B) y arnés (C). 


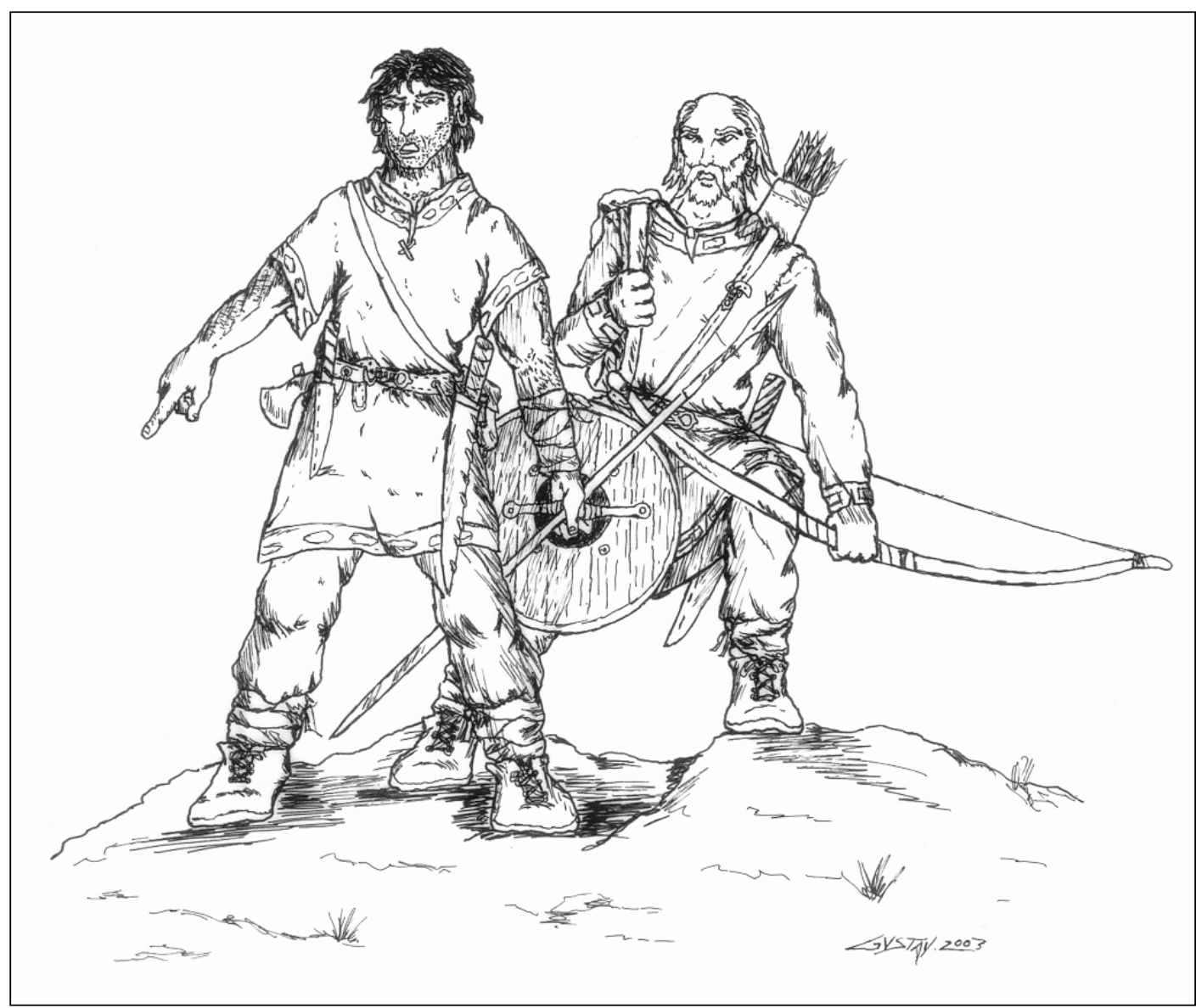

Fig. 12. Restitución ideal del equipo de infantería ligera visigoda para la zona estudiada (principios del siglo VIII) a partir del material comentado.

Un primer conjunto (Fig. 12) que se relacionaría con la infantería ligera podría incluir bien una panoplia a partir de jabalinas (Fig. 7, 1) y hachas arrojadizas (Fig. 6, 2-3) como armas principales, quizás añadiendo alguna lanza de mano ligera (Fig. 9, 7) y un escudo poco pesado (tipo II) para protección a corta distancia; o bien una panoplia más sencilla basada en arcos y flechas (Fig. 9, 1) junto con alguna arma corta de tipo sax (Fig. 3, 11) o scramasax. En este grupo también se incluirían las armas eventuales, «de fortuna», empuñadas por gentes de condición modesta.

Otra combinación de armas para infantería más pesada (Fig. 13) se basaría en las lanzas de mano (Fig. 8, 3-4) con regaton (Fig. 9, 8-9) como armas de choque, alguna espada o scramasax para el cuerpo a cuerpo, una jabalina pesada o francisca para lanzar a corta distancia, y una protección basada en escudos pesados del tipo III.

Un último tipo de panoplia (Fig. 14) se relacionaría con la caballería, incluyendo grandes lanzas de choque como SJR-6 (Fig. 9, 6) con escudos pequeños (tipo I) o bien autenticas lanzas de caballería a dos manos (Fig. 8, 5). El equipo del caballo se completaría con bocados (PR- A, SJR-B) y hebillas de distintos tipos. Este tercer grupo viene a representar el grado más alto en la escala social visigoda, y seguramente se asociaría a las noblezas locales, quienes debían complementar su panoplia con protecciones corporales costosas como los cascos metálicos o las cotas de malla. 


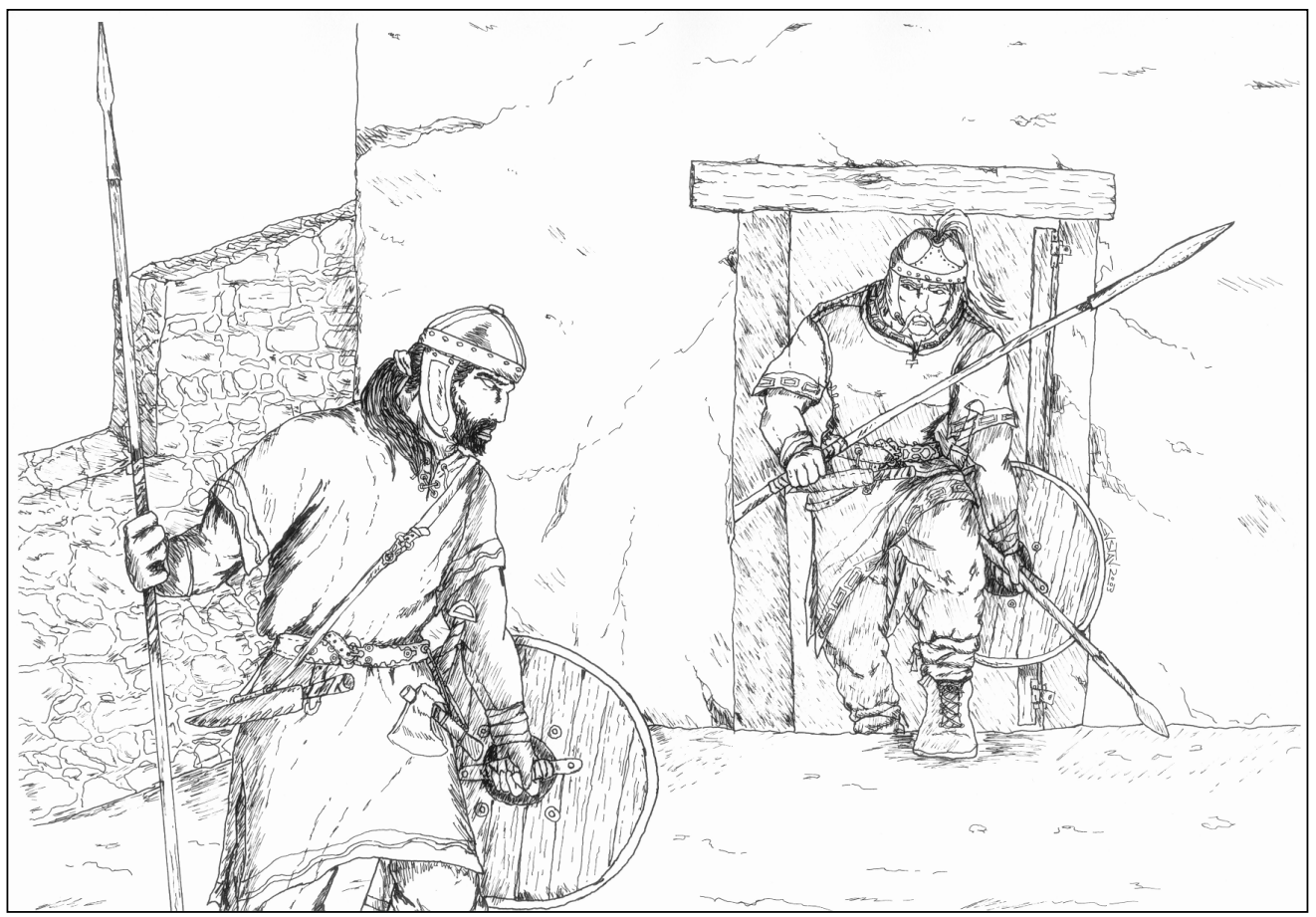

Fig. 13: Restitución ideal del equipo de infantería pesada visigoda para la zona estudiada (principios del siglo VIII) a partir del material comentado.

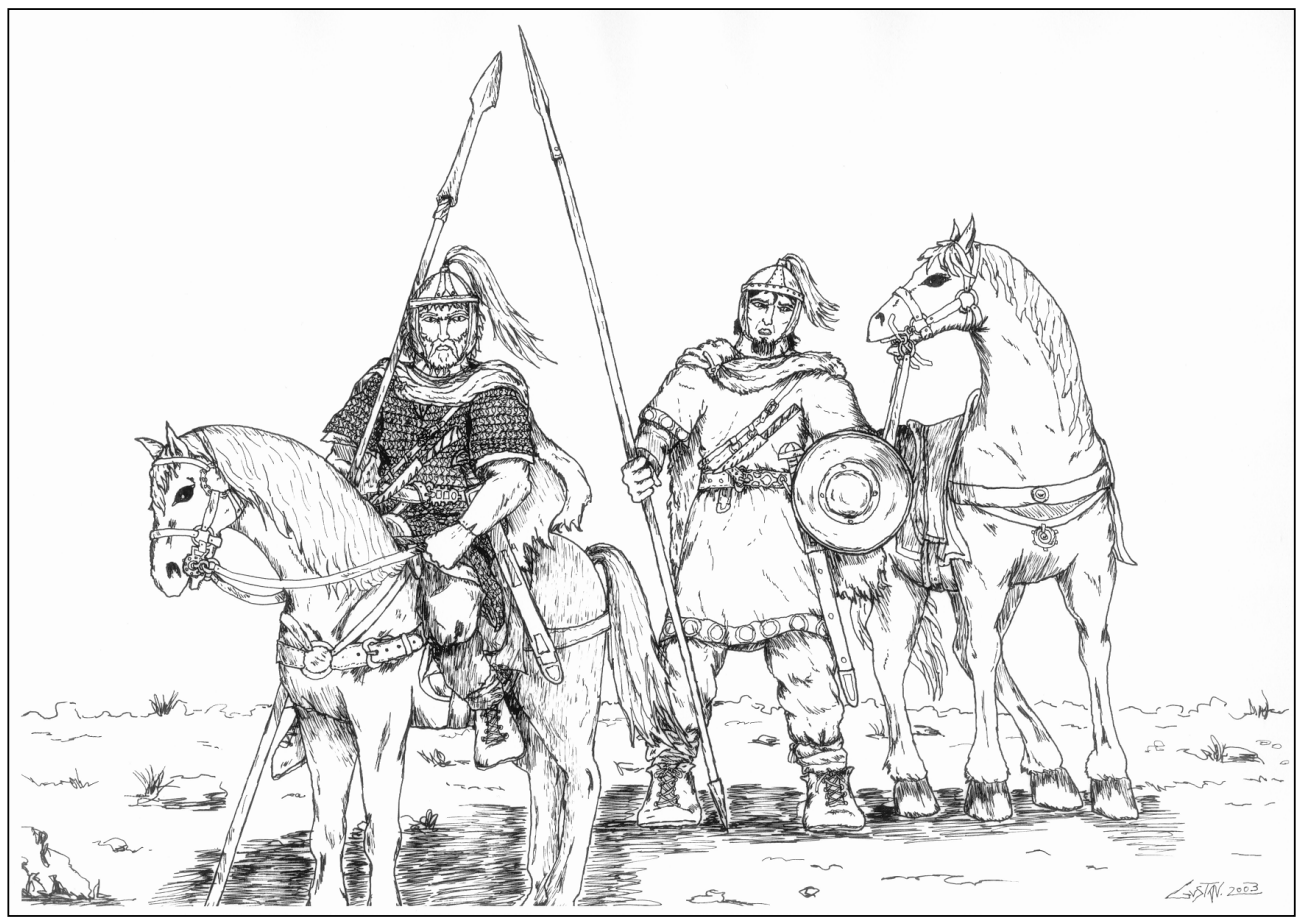

Fig. 14: Restitución ideal del equipo de caballería visigoda para la zona estudiada (principios del siglo VIII) a partir del material comentado. 
Esta caballería hay que entenderla, y así lo confirman estas armas, como caballería pesada y no de hostigamiento, y de ella tenemos claros antecedentes ya desde el Bajo Imperio (Lebedynsky, 2001: 35 y ss.) entre los visigodos. En la etapa final de la ocupación visigoda peninsular, las tácticas de caballería no habrían evolucionado demasiado con respecto a las de época bajoimperial romana. El desarrollo de maniobras de caballería más complejas no vivirá su momento hasta bien avanzado el siglo VIII (White, 1973; Contamine, 1984: $230 \mathrm{y}$ ss.), en que el estribo tendrá su difusión en Europa occidental y acabará facilitando al jinete una sujeción más segura para la carga.

Habría que añadir todos los equipos sus respectivos cinturones con distintos tipos de hebilla y sus cuchillos suspendidos a través de tiras de cuero enlazadas a arandelas broncíneas remachadas en aquellos ${ }^{17}$.

Algunas de las piezas tratadas (franciscas, sax, framea, hebillas del tipo SJR-3 (Fig. 10, 3)y quizás alguna lanza tipo PR-3 (Fig. 8,3) parecen tener parentesco con el equipamiento merovingio, lo cual apunta hacia una relación, hasta cierto punto lógica en una zona tan próxima, con el mundo franco. Sin embargo, no creemos que haya que dejarse llevar por esta idea, puesto que algunos de estos tipos, que suelen aparecer como armas «nacionales» francas, estan bien representados entre los visigodos por las fuentes literarias. La explicación a esta interacción se debe a la relativa homogeneización del armamento de los pueblos germánicos (Lebedynsky, 2001: 7-8) a consecuencia de la rápida difusión de estilos, equipamientos y tácticas vivida durante las invasiones.

Como hemos visto, existen todavía puntos oscuros en el estudio de la panoplia visigoda que no permiten comparar los hallazgos del noreste peninsular con los de otras zonas, y habrá que esperar a la realización de nuevos hallazgos (dentro y fuera de esta región) y a la publicación de trabajos pendientes para intentar esclarecerlos mínimamente.

\section{AGRADECIMIENTOS:}

Al Museu d'Arqueologia de Catalunya-Girona, y muy especialmente a su directora $\mathrm{Au}-$ rora Martín por facilitarnos el acceso a los materiales de Puig Rom.

Al equipo de excavación de 1'Institut del Patrimoni Cultural de 1'Universitat de Girona, y particularmente a Jordi Sagrera, quien dibujó parte del material de Sant Julià de Ramis.

GuSTAVO GARCÍA JiMÉNEZ

C/Miquel Rosset, 33, 1-1-17488 Cadaqués (Girona)-e-mail: gust_mei@hotmail.com

DAVId VIVÓ I Codina

Profesor titular de Arte Antiguo de la Universitat de Girona.

Institut de Patrimoni Cultural de la Universitat de Girona.

Plaça Ferrater Mora, 1 - 17071 Girona - e-mail: david.vivo@udg.es

17 Hay ejemplos de estas arandelas en Sant Julià de Ramis (VV.AA., en prep.). 


\section{BIBLIOGRAFÍA}

ARDANAZ, F; RASCÓN, S.; SÁNCHEZ, A. (1998): Armas y guerra en el mundo visigodo. Los visigodos y su mundo (Madrid, 1990). Revista de Arqueología, Paleontología y Etnologia, 4: 411-449. 1998.

AzKARATE, A. (1998): Aldaieta. Necrópolis tardoantigua de Aldaieta (Nanclares de Gamboa, Alava): Vol. I. Memoria de la excavacion e inventario de los hallazgos. Memorias de yacimientos alaveses 6, Alava 1998

Bishop, M. C.; Coulston, J. C. N (1993): Roman Military Equipment from the Punic Wars to the fall of Rome. Ed. Bastford, London 1993.

BRUHN DE HOFFMEYER, A. (1972): Arms and armour in Spain: a short survey. Vol. 1. Instituto de estudios sobre armas antiguas. CSIC.1972.

Burch, J.; Nolla, J. M.; PALAhÍ, Ll.; SAGRera, J.; SuREDA, M.; VivÓ, D. (2001): Excavacions a la muntanya de Sant Julià de Ramis 1: El sector de l'antiga esglèsia parroquial. 2001.

Burch, J.; Nolla, J. M.; PAlahí, Ll.; Sagrera, J.; SuReda, M.; VivÓ, D. (2002): Excavacions al poblat de Sant Julià de Ramis. 6 Jornades d'Arqueologia de les comarques gironines. Sant Joan de les Abadesses, 2002.

Contamine, P. (1984): La guerra en la Edad Media. Ed. Labor. Buenos Aires 1984.

DIETZ, L. (1990): Pferdegeschirr des frühen reiternomaden in Römish-Germanischen Zentralmuseums. Jahrbuch des Römisch-Germanisches Zentralmuseum Mainz 37.2. Mainz 1990.

FernandeZ-Godin, S.; Perez de BARRAdAS, J. (1931): Excavaciones en la necrópolis visigoda de Daganzo de Arriba (Madrid). Memorias de la Junta Superior de Excavaciones Arqueológicas 114. Madrid 1931.

HeRnÀndez CARDona, F. X. (2001): Història militar de Catalunya. Vol. 1: Dels ibers als carolingis. Ed. Francesc Dalmau. Barcelona 2001.

JOFFROY, R. (1974): Le cimetière de Lavoye. Necropole mérovingienne, Ed. A-J.Picard. Paris 1974.

LEBEDYNSKY, I. (2001): Armes et guerriers barbares au temps des grandes invasions (IV au VI siècle apr. J-C). Ed. Errance. Paris 2001.

MCDowall, S.; MCBRIDE, A. (1996): Germanic warrior. Osprey military. Warrior Series 17. Oxford 1996.

PAlOl SAlEllas, P. de (1950): Fíbulas y broches de cinturón de época visigoda en Cataluña. $A r-$ chivo Español de Arqueologia 78, 1950.

Palol Salellas, P. de (1952a): Castro hispanovisigodo de «Puig-Rom» (Rosas). Informes y Memorias 27, 1952: 163-197.

Palol Salellas, P. de (1952b): Algunas piezas de adorno de arnés de época tardorromana e hispanovisigoda. Archivo Español de Arqueología 86. Madrid 1952: 297-319.

PALOL, P. de (1956): Esencia del arte hispánico de época visigoda: romanismo y germanismo. Settimane di Studio del Centro Italiano di Studi sull'Alto Medioevo, T.III: I Goti in Occidente, problemi. Espoleto, 1956 : 65-125.

PALOL, P. de (1972): Una tumba romana de Toledo y los frenos de caballo hispanorromanos del Bajo Imperio. Pyrenae 8.Barcelona 1972: 133-149.

PÉREZ SÁNCHEZ, D. (1989): El ejército en la sociedad visigoda. Madrid 1989.

RIPOLl LóPez, G. (1998): Toréutica de la Bética (siglos VI y VII d.C.). Reial Academia de les Bones Lletres. Barcelona 1998.

SALIN, E. (1957): La civilisation mérovingienne. Vol. III: les techniques. Paris 1957. 
SCHULZE-DÖRRLAMM, M. (1985): Germanische kriegergräber mit schwertbeigabe in Mitteleurope aus dem speïten 3. Jahrhundert und der ersten hälfte des 4. Jarhunderts $n$. chr. Zur entstehung der waffenbeigabensitte in Gallien. Jahrbuch des Römisch-Germanisches Zentralmuseum, Mainz 32. Mainz 1985: 509-569.

SIM, D. (1995): Weapons and mass production. vanDriel-Murray (ed.):Proceedings of the Ninth International Roman Military Equipment Conference. Leiden 1994. Journal of Roman Military Equipment Studies 6.

TARACEna AguirRe, B. (1926): Excavaciones en diversos lugares de la provincia de Soria. Junta Superior de Excavaciones Arqueológicas 75. 1926.

VV.AA. (1999): Del romà al romànic: història, art i cultura de la Tarraconense mediterrània entre els segles IV i X. Barcelona 1999.

Vv.AA. (en preparación): Excavacions a la muntanya de Sant Julià de Ramis 2.

WHITE, L. (1973): Tecnología medieval y cambio social. Buenos Aires 1973. 